\title{
Territorial efficiency: Analysis of the role of public work safety controls
}

\author{
Esteban Lafuente \\ Department of Management, Universitat Politècnica de Catalunya (UPC Barcelona Tech) \\ EPSEB, Av. Gregorio Marañón, 44-50, 08028 Barcelona, Spain \\ E-mail: esteban.lafuente@upc.edu \\ Jesús Abad \\ Department of Management, Universitat Politècnica de Catalunya (UPC Barcelona Tech) \\ EPSEB, Av. Gregorio Marañón, 44-50, 08028 Barcelona, Spain \\ E-mail: jesus.abad@upc.edu
}

\begin{abstract}
This study analyzes the efficiency of Spanish provinces in a model that incorporates occupational health and safety (OHS) policy controls and work accidents into the analysis. Building on productivity models rooted in non-parametric frontier methods, namely Data Envelopment Analysis, the proposed approach allows the development of a production function that accurately models the joint production of desirable (GDP) and undesirable (work accidents) outputs. The efficiency analysis of the 50 Spanish provinces during 2003-2012 reveals that territories that drastically cut resources dedicated to OHS controls - in our case, safety inspections and economic sanctions for safety violations - show higher inefficiency levels. Nevertheless, the changes in OHS policies introduced by Spanish provinces after the change in the state of the economy in 2008 had a heterogeneous impact on their efficiency level. Effective OHS policy is not necessarily linked to merely implementing more OHS policy controls, but rather to the capacity of territories to efficiently allocate their available OHS resources and monitor business activity. Policy implications and future research avenues are discussed.
\end{abstract}

Keywords: Work accidents, economic cycle, OHS policy, work safety controls, data envelopment analysis, directional distance function, territorial efficiency

JEL codes: C14, J28, O47

\section{Draft version: November 2020}

\section{Cite as:}

Lafuente, E., Abad, J. (2021). Territorial efficiency: Analysis of the role of public work safety controls. Safety Science, 134, 105074. doi: https://doi.org/10.1016/j.ssci.2020.105074 


\section{Territorial efficiency: Analysis of the role of public work safety controls}

"The purpose of health and safety regulation is to protect people at work and rightly so. But we need common sense at the heart of the system, and these measures will help root out the needless burden of bureaucracy."

—Chris Grayling, Work and Pensions Minister, UK (The Guardian, March 20 2011). ${ }^{1}$

\section{Introduction}

Occupational health and safety (OHS) constitutes a fundamental pillar that contributes to the appropriate functioning of territories' productive structures. By promoting the development of safer work environments, safety policies help to stimulate social wealth and, consequently, territorial economic outcomes (Ruser and Butler 2009, Piore and Schrank 2018).

In the European context, governments have primarily allocated considerable resources to enhance work safety conditions, either through specific policies or investments among competing businesses (European Commission 2007). Statistics made available by the European Agency for Safety and Health at Work (EU-OSHA 2013) reveal that the economic costs of work accidents to governments, businesses, and workers account for 3\% of the EU's GDP. The increased awareness of the relevance of work safety has led European policy makers to implement specific policies within the EU 2020 strategic plan with the objective to stimulate safer work conditions and, ultimately, territorial performance (European Commission 2014).

Both production and work safety are highly relevant, connected policy objectives (Ruser and Butler 2009). However, the specific analysis of the joint effect over territories' efficiency of economic objectives—in terms of resource exploitation—and policy actions oriented to improve work safety conditions remains largely sidelined in prior research.

Existing research rooted in the economic literature has traditionally modeled territorial outpute.g., GDP — as a function of the capital employed by businesses to generate goods and services and labor measured as the number of workers in the economy (e.g., Kumar and Russell 2002, Caselli and Coleman 2006). Another research stream, inspired in the work of Kossoris (1938) and more related to

\footnotetext{
${ }^{1}$ http://www.theguardian.com/politics/2011/mar/21/health-safety-inspections-cut-third
} 
the social science and the occupational health and safety frames, has proposed an empirical relationship between the state of the economy and work accidents rates on the basis that variations in work accident rates are explained by economic fluctuations often operationalized via changes in economic outputs (e.g., Nichols 1989, Boone et al. 2011, Song et al. 2011, Lafuente and Daza 2020).

To the best of our knowledge these two streams of literature do not converge. This is the core of this study. In our view, the debate is open and we address this absence of convergence-which we find somewhat striking given the relevance of work safety for regulators and other stakeholders (e.g., businesses and workers)—by investigating the following research questions. On the one hand, if work accidents are primarily driven by the state of the economic cycle (i.e., growth or recession): are OHS systems symbolic (sterile) policy instruments unconnected to territories' production function and, consequently, to their efficiency level? On the other hand, if OHS systems do help to improve work safety at the territorial level: should OHS policy become the norm given that territories can achieve better OHS results by simply deploying more resources to OHS preventive interventions?

Although work safety is normatively and regulatory legitimate-i.e., the construct is consistent with societal values and existing laws, respectively (Scott 2001)—in most countries, the relevance of these questions flows from the importance of learning how policy makers can accommodate different objectives (i.e., economic and OHS goals) which are simultaneously embedded in the institutional setting and, consequently, impact territories’ efficiency.

To address the study questions empirically, we propose that work accidents are undesirable workrelated outcomes of the economic activity and that, because of the connection between GDP and work accidents, OHS policy controls play a critical role in shaping territorial efficiency by contributing to minimize work accidents. Specifically, we scrutinize the efficiency of the 50 Spanish provinces during 2003-2012 in the presence of OHS objectives. The proposed technology function incorporates the simultaneous production of desirable (GDP) and undesirable (work accidents) outputs, and allows territories to employ OHS policy controls—which we link to safety inspections and economic sanctions—-to minimize work accidents.

Underlying our approach to model territorial efficiency — in which GDP and work accidents are jointly produced—are two elements that constitute the cornerstones upon which we built the study. 
The first critical aspect deals with the analysis of the theoretical connection between economic activity and work accidents. Work safety is an attractive concept and, echoing the seminal work by Kossoris (1938), researchers have devoted a great deal of efforts on evaluating the relationship between territorial outcomes, often linked to GDP levels, and work accident rates (Ruser 1985, Lanoie, 1992, Davies et al. 2009, Boone et al. 2011, Song et al. 2011, Lafuente and Daza 2020). In this discussion, a common presumption is that the state of the economic cycle (expansion or recession) affects the exploitation of production factors — in particular employment—so, therefore, the state of the economy is a potent factor explaining the longitudinal variations in work accident rates across territories.

This logic is used to explain the evolution of work accident rates in periods of economic growth and recession. In periods of economic expansion, businesses tend to increase operations to satisfy market demands, which improve employment figures. Arguably, two effects of this process lead to a raise in the rate of work accidents: first, the work intensification effect that links higher work accident rates to increased workloads of both experienced and new (possibly inexperienced) workers (Nichols 1989, Asfaw et al. 2011); and second, the notification effect associated to the greater reporting of accidents by workers because of their relatively low cost of finding a job in the market (Gerdtham and Ruhm 2006, Davies et al. 2009).

On contrary, behavioral and labor-market factors have been invoked to explain the fall in work accident rates when the economy shrinks. Prior studies suggest that the positive correlation between macroeconomic variables and work accidents (excluding fatalities) in recession periods is caused by a reduction in the workers' willingness to report minor accidents due to fear of losing their job (claim reporting effect) (Boone and van Ours, 2006). Also, the properties of labor markets may explain the decrease of work accidents in recession periods. The most preferred mechanism used by businesses to survive the hard times is downsizing the workforce. But, in most EU countries (including Spain) firing long-tenure employees is a costly process, so businesses have strong incentives to fire young, inexperienced workers who arguably have a greater probability to experience work accidents (De la Fuente et al. 2014).

Despite these rigorous efforts, studies in this tradition-i.e., analysis of the territorial performance-work accidents relationship—indirectly assume that the institutional setting governing 
work safety (e.g., regulation, policy actions and controls) evenly affects territories’ work accident rates, and that the statistical significance of the relationship between economic cycles and work accident rates represents a test of the effectiveness of regulatory frameworks.

Nevertheless, the prioritization of relevant economic and work safety policies follow different decision making processes. For example, although the EU have launched initiatives to enhance occupational health and safety (European Commission 2014), OHS preventive policies have suffered important budget cuts after 2008 (safety inspections fell by 25\% between 2009 and 2013) (European Commission 2013). At the same time, the EU has mobilized economic resources through support policies-e.g., the program for the Competitiveness of Enterprises and Small and Medium-sized Enterprises (COSME) endowed with a 2.3 billion Euro budget between 2014 and 2020-in order to promote the development of competitive SMEs.

These examples are in line with the notion that territories pursue multiple goals beyond economic-maximizing objectives. Territorial performance has often been conceptualized as the result of the amalgamation of production (see, e.g., Kumar and Russell 2002, Caselli and Coleman 2006) and other relevant policy functions (see, e.g., Lundvall (1992) for an analysis of innovation systems, Acemoglu et al. (2012) for a debate on the role of environmental policies on economic growth, and Acs et al. (2014) and Lafuente et al. (2019) for a discussion of the relevance of the national system of entrepreneurship). Because economic activity and work accidents are inherently connected (Nichols, 1989, Boone et al. 2011), we propose that the analysis of territorial performance should include the safety function encompassing the rules governing the organization of inputs linked to OHS interventions. Differences in resource allocation condition the effectiveness of any policy, including those targeting OHS objectives (e.g., lower work accident rates). This may explain the dissimilar capacity of territories for realizing the generally positive effects of OHS policy interventions.

These arguments are at the core of the second cornerstone that motivates our study, which deals with the computation of a territorial efficiency model that considers the joint production of desirable (GDP) and undesirable (work accidents) outputs.

At the territorial level, economic resources dedicated to maximize economic outcomes (e.g., GDP) interact with OHS resources and controls that seek to minimize the negative consequences of 
economic activity (in our case, work accidents). Thus, it seems plausible that the simultaneous exploitation of economic and OHS-related resources shape territorial efficiency. The appropriate representation of the technology function is decisive for performance assessments, and the distinction between good (desirable) and bad (undesirable) outputs pushes us to rethink the way we model their simultaneous production.

To accurately capture the territorial effects of the joint production of desirable (GDP) and undesirable (work accidents) outputs, we employ the directional distance function (DDF) (Färe et al. 1989, Kuosmanen 2005) rooted in non-parametric techniques (i.e., Data Envelopment Analysis) to compute efficiency scores of Spanish provinces. By employing linear programming, this approach is more suitable to estimate efficiency scores in complex settings where multiple inputs generate multiple outputs (Grifell-Tatjé and Lovell 2015). Also, and contrary to parametric methods (e.g., stochastic frontier or regression models), the flexible nature of DDF models—which does not impose assumptions on the functional distribution—is especially appealing to model the territories' production technology by allowing for multiple outputs to be pursued. Therefore, the drawn technology based on the DDF is an appropriate tool to reach our main objective (i.e., analysis of territories' efficiency via a production function in which desirable outputs (GDP) are maximized and undesirable outputs (work accidents) are minimized simultaneously), and is compatible with the core of operations management research (i.e., transforming inputs into outputs in an efficient way) (Wiengarten et al. 2017, p. 30).

For the proposed analysis of the 50 Spanish provinces (NUTS-3 level) during 2003-2012, we created a unique dataset that includes information from multiple sources (Spanish Institute of Statistics and Spanish Ministry of Employment and Social Security). The Spanish setting is attractive for various reasons. First, after the implementation of the Prevention of Occupational Risks Act in 1995 that sought the harmonization with EU regulation, policy makers promoted various reforms to address weaknesses that became evident over time, including, for example, the need to monitor OHS practices of subcontracting firms participating in the construction industry, and the simplification of OHS procedures for SMEs. These reforms endowed public administrations with the resources and mechanisms—e.g., new procedural instruments, prevention representatives, regulation of external prevention services - to encourage the compliance with OHS norms (Fernández-Muñiz et al. 2018). 
From a policy point of view, the analysis of OHS controls may provide valuable information on the effectiveness of Spain's OHS system. Second, data available from the Spanish Occupational Health and Safety Institute (INSHT 2015) reveals that 78\% of Spanish firms delegate OHS practices to external prevention service firms. This reinforces our argument on the relevance of studying the role of OHS preventive controls on territorial efficiency in periods of economic growth and recession.

The importance of this study stretches beyond a purely economic discussion and has implications within the area of operations management and territorial performance. By incorporating the safety function — which links the use of policy safety controls to mitigate work accidents—in the territories' production function, we offer a novel perspective that contributes to unveil how policy makers can orchestrate territories’ resources to fully realize the potential benefits from the mutual relationship between economic and OHS outputs. Instead of studying temporal patterns between economic and work safety measures, we analyze territorial efficiency in a model that incorporates OHS policy controls that seek to minimize work accident rates by promoting OHS practices and disciplining businesses. The analysis of the connection between economic outputs and OHS interventions sheds light on what policies may contribute to capitalize on available OHS resources and, ultimately, lead to a greater economic consolidation.

\section{The safety function in Spain: The governance of OHS policy actions and interventions}

This section briefly describes the main aspects of the rules and regulations governing the organization of policy OHS interventions designed to alleviate work accidents in Spain, a system that we call the safety function.

Contrary to the US model whose OHS regulation is characterized by high levels of decentralization, specialized safety inspectors and deterrence-oriented penalization; in Spain the regulatory framework governing workplace safety-i.e. the safety function—is inspired in the generalist, compliance-oriented model developed in France (Piore and Schrank 2018).

Since its creation in 1906, the Spanish work inspectorate (Inspección de Trabajo y Seguridad Social, ITSS hereafter) is the governmental agency that evaluates labor conditions and work safety practices of Spanish businesses and, if necessary, establishes corrective actions and economic 
sanctions with the objective to ensure appropriate working conditions. The Spanish inspectorate (ITSS) is part of the Spanish Ministry of Labor, Migration and Social Security, and it has a centralized organizational structure headquartered in Madrid, with offices located in each of the country's provinces that work in coordination to ensure labor standards (ITSS: http://www.empleo.gob.es/itss/web/Quienes_somos/Organigrama/index.html).

After various reforms focused on improving the functioning of the ITSS without modifying its generalist approach, the ITSS Act (Spain 1997) and the Royal Decree 138/2000 (Spain 2000a) are the current legal frameworks regulating the functioning of the Spanish inspectorate. Also, and in order to achieve greater harmonization with EU regulation, the Prevention of Occupational Risks Act (Law 31/1995) (Spain 1995) equips safety inspectors with a set of procedural tools and instruments necessary to reach the operational objectives of the ITSS across the Spanish provinces. More specifically, the Law 31/1995 (Spain 1995) defines two types of intervention so that safety inspectors can fulfill their core operational tasks (inspections), namely advisory activities and monitoring and disciplinary activities.

The first type of intervention relates to the capacity of safety inspectors for providing information and advice to businesses and workers on how to create and maintain a safe work environment as well as on how to comply with OHS regulations (Spain 1995, article 9).

Concerning the second type of intervention, the Law 31/1995 (Spain 1995, article 43) establishes a set of uniform procedures nationwide that enables inspectors to execute three types of monitoring and disciplinary actions as a result of the safety inspection: 1) safety reports including OHS issues that should be addressed and the proposed corrective actions, 2) temporal shutdown of business operations, and 3) the imposition of economic sanctions as a result of safety violations following the parametersi.e., the severity of safety violations and the number of workers affected—set by the Royal Decree 5/2000 (Spain 2000b, article 40).

Although the two types of policy OHS interventions are highly parameterized, it should be kept in mind that regulation does not include specific procedures to select the businesses that will be inspected. Therefore, ITSS offices enjoy a great flexibility to manage OHS resources (e.g., inspectors, 
information), and safety inspectors are empowered to exercise their discretion when it comes to prioritize targets for OHS inspections.

In sum, the Spanish generalist system—characterized by a centralized structure, a strong emphasis on compliance and advice, and high flexibility that allows inspectors to decide which businesses to oversee-is an archetypal case of the French inspectorate which is conducive to enhanced competitiveness (via advice) and compliance (via monitoring and disciplinary interventions); a process that Piore and Schrank (2018, p. 12) call 'root-cause regulation'. Also, the analysis of the Spanish inspectorate suggests that safety inspectors use uniform criteria both to evaluate businesses' labor conditions and to impose disciplinary measures as a result of safety violations. This is especially relevant for our study as it further justifies the proposed analysis of the role of the OHS policy controls on the efficiency level of Spanish provinces.

\section{Modeling territorial efficiency in the presence of desirable and undesirable outputs via directional distance functions}

The approach adopted in this study to compute the efficiency level of the 50 Spanish provinces is non-parametric. This section describes the production function used in this study. Section 3.1 briefly introduces the baseline DEA model, while section 3.2 presents the directional distance function used to model the joint production of good and bad outputs.

\subsection{Data envelopment analysis (DEA)}

Literature rooted in economic production theory often employs Data Envelopment Analysis (DEA) frontier methods to evaluate the efficiency of units employing a set of (potentially multiple) inputs to generate a set of (potentially multiple) outputs (Cook and Seiford 2009, Cooper et al. 2011, Grifell-Tatjé and Lovell 2015). This data-driven non-parametric method uses linear programming to approximate the true technology without imposing any restriction on the sample distribution. Underlying DEA models is the fundamental technological assumption that the units of analysis (in our case, provinces) (i) use $\mathbf{x}=\left(x_{1}, \ldots, x_{J}\right) \in R_{+}^{J}$ inputs to produce $\mathbf{y}=\left(y_{1}, \ldots, y_{M}\right) \in R_{+}^{M}$ outputs, and that 
this input-output set forms the technology $(T): T=\{(\mathbf{x}, \mathbf{y}): \mathbf{x}$ can produce $\mathbf{y}\}$. DEA is a benchmarking method that generates an empirical technology frontier that is used to determine the units' efficiency: units positioned on this surface are deemed as efficient, while for the rest of observations DEA estimates an efficiency score that represent their distance to the best practice frontier.

The technology $(T)$ is modeled for each unit of analysis (i) in the sample $(N)$ via an input or output distance function. For example, the following output-oriented DEA model can be used to evaluate the efficiency level of a set of units of analysis: $D(\mathbf{x}, \mathbf{y})=$ in $(\Theta>0:(\mathbf{x}, \mathbf{y} / \theta) \in T)$, where the infimum can be interpreted as the maximum possible expansion in outputs given the input level, and $T$ is the linear piecewise technology:

$$
T=\left\{\sum_{i=1}^{N} \lambda_{i} \mathbf{y}_{i, m} \geq \theta_{i} \mathbf{y}_{i, m}, m=1, \ldots, M, \sum_{i=1}^{N} \lambda_{i} \mathbf{x}_{i, j} \leq \mathbf{x}_{i, j}, j=J, \sum_{i=1}^{N} \lambda_{i}=1, \lambda_{i}>0, i=1, \ldots, N\right\}
$$

The solution value of $\theta$ is the efficiency score computed for the ith unit of analysis, and for efficient units $\theta=1$ while for inefficient units $\theta>1(\theta-1$ is the inefficiency level). In words, this technology models units' output (y) as a function of their resources (x). The term $\lambda$ is the intensity weight vector used to estimate the linear combinations of the analyzed units $(N)$. A variable returns to scale technology is modeled by adding the restriction $\sum_{i=1}^{N} \lambda_{i}=1$ (a constant returns to scale technology can be modeled by removing this restriction) (Cooper et al. 2011).

Efficiency assessments based on DEA models have been conducted in a variety of fields (Ray 2004, Cook and Seiford 2009). Nevertheless, the standard DEA model presented above maximizes all outputs, regardless of whether they are desirable or undesirable. That is, this model does not differentiate desirable outputs from the undesirable outputs that are jointly produced with good outputs. Therefore, the next section elaborates on the directional distance function that correctly models the simultaneous production of good and bad outputs.

\subsection{The simultaneous production of desirable and undesirable outputs in efficiency models}

The increased awareness of the usefulness of DEA models together with the need to accurately describe production technologies has led to develop a research stream that, besides canonical DEA 
models evaluating inputs and desirable outputs (see section 3.1), introduces undesirable outputs in the analysis (Kuosmanen 2005, Ray et al. 2018). Studies addressing the joint treatment of good and bad outputs are relatively common in the banking literature (e.g., Park and Weber 2006, Barros et al. 2012, Epure and Lafuente 2015, Pham and Zelenyuk 2018) and, at the territorial level, in environmental research (e.g., Färe et al. 2004, Kumar 2006, Sueyoshi and Goto 2011, Murty and Russell 2018).

In contexts where desirable and undesirable outputs are jointly produced, efficiency analyses often employ directional distance functions (DDF) (Chung et al. 1997). The output directional distance function $\left(\vec{D}_{O}(x, y, b)\right)$ is used in this study to estimate efficiency scores that allow for a simultaneous increase in good output and reduction in bad output. Building on the work by Chambers et al. (1996) and Chung et al. (1997), the production technology (T) in DDF models with good and bad outputs is represented by a vector of inputs $\left(\mathbf{x}=\left(X_{1}, \ldots, X_{J}\right) \in R_{+}^{J}\right)$ that can simultaneously produce a vector including desirable $\left(\mathbf{y}=\left(y_{1}, \ldots, y_{M}\right) \in R_{+}^{M}\right)$ and undesirable $\left(\mathbf{b}=\left(b_{1}, \ldots, b_{k}\right) \in R_{+}^{K}\right)$ outputs: $T=\{(\mathbf{x}, \mathbf{y}, \mathbf{b}): \mathbf{x}$ can produce $(\mathbf{y}, \mathbf{b})\}$.

The following linear program models the described technology $\left(\vec{D}_{O}(x, y, b)\right)$ and computes, for each province (i), the efficiency scores:

$$
\begin{array}{lll}
\vec{D}_{O}\left(x_{i}, y_{i}, b_{i}\right)=\max \theta_{i} & \\
\text { subject to } & \sum_{i=1}^{N} \lambda_{i} y_{i, m} \geq(1+\theta)_{i} y_{i, m} & , m=1, \ldots, M \\
& \sum_{i=1}^{N} \lambda_{i} b_{i, k}=(1-\theta)_{i} b_{i, k} & , k=1, \ldots, K \\
& \sum_{i=1}^{N} \lambda_{i} x_{i, j} \leq x_{i, j} & , j=1, \ldots, J \\
& \sum_{i=1}^{N} \lambda_{i}=1 ; \lambda_{i} \geq 0 & , i=1, \ldots, N
\end{array}
$$

The output directional distance function in equation (1) is a measure of efficiency that simultaneously accounts for the maximum expansion in good output (y) and contraction in bad output (b). In equation (1) the term $\theta_{i}$ is the efficiency score computed for each province. Note that for efficient provinces $\theta_{i}=0$, while for inefficient provinces the result of the efficiency score $\left(\theta_{i}>0\right)$ points to the degree of inefficiency. The term $\lambda$ is the intensity weight vector used to estimate the 
linear combinations of provinces $(N)$, while the restriction $\sum_{i=1}^{N} \lambda_{i}=1$ imposes variable returns to scale to the technology.

In the context of the proposed convex DDF technology (equation (1)) there are four properties that are worth highlighting. First, note that we adopt an output-oriented DDF model to draw the provinces' technology. In our interpretation, increased territorial performance signals greater local demand and economic activity. Thus, instead of higher business exit rates and labor cuts, from a policy perspective the improvement of territorial performance through the optimal exploitation of available resources (in our case, businesses and labor) is the main goal of most policy makers (Färe et al. 1994, Kumar and Russell 2002).

Second, the proposed DDF technology modeling the joint production of desirable and undesirable outputs assumes that inputs and good outputs are strongly disposable, and that good and bad outputs are jointly weakly disposable. Strong disposability of inputs implies that they do not congest outputs. In words, an increase (or not decrease) in input consumption will not shrink the output level. By imposing strong disposability of good outputs, the technology in equation (1) assumes that for any observed (feasible) vector of good and bad output an alternative output vector with more good output and the same level of bad output is also feasible. One interpretation for this assumption is that territories can 'freely' dispose of good output (GDP) without additional costs (work accidents).

Weak disposability of good and bad outputs means that, for a fixed input level, the reduction of bad outputs (a costly process) is associated to the production of less total output. This constraint- the strict equality on the bad output constraint together with the inequality on the good output constraint in equation (1) - introduces the concept of a costly rather than free disposal of bad outputs. In the context of this study, this restriction is connected to the role of safety controls on the efficiency of the analyzed provinces. Our model acknowledges the role of safety controls and imposes that provinces cannot freely expand their level of good (GDP) and bad (work accidents) outputs. In this sense, the cost of reducing bad outputs—i.e., work accidents—can be due to the imposition of greater disciplinary controls via economic sanctions. Alternatively, policy makers might choose to meet safety 
targets by increasing the monitoring of businesses’ activity (e.g., increasing the number of inspections), with the same effect. ${ }^{2}$

Third, our DDF model accurately captures the nature of the relationship between good and bad outputs by imposing that the desirable and undesirable outputs are null-joint. In words, work accidents are an unintended consequence of economic activity, and our model assumes that it is not possible to produce GDP without simultaneously producing work accidents. Also, equation (1) assumes that the only feasible way to report zero work accidents is by shutting down the economic activity (GDP = 0) of provinces. This property is in line both with our argument that economic activity produces work accidents and with prior evidence indicating that GDP and work accidents are inherently connected (Asfaw et al. 2011, Boone et al. 2011).

Fourth, note that the use of the directional distance function implies the definition of the directional vectors $\left(\mathbf{g}=g_{x}, g_{y}, g_{b}\right)$ that specify the direction in which each unit is projected on the efficiency frontier. By construction the output DDF seeks to simultaneously expand the good output in the direction $g_{y}$ and decrease the bad output in the direction $g_{b}$, while keeping the input vector at a constant (observed) level $\left(g_{x}=0\right)$ (Chung et al. 1997, Podinovski and Kuosmanen 2011). This approach is in line with our argument that provinces pursue both the maximization of their good output (GDP) as well as the minimization of the consequences of their economic activity (work accidents). Also, as mentioned above, by keeping fixed the input level $\left(g_{x}=0\right)$ we assume that business exits and labor cuts are not policy objectives. Accordingly, we use the directional vector $\mathbf{g}=\left(0, g_{y},-g_{b}\right)$ in our analysis.

To aid in the interpretation of the efficiency scores computed via equation (1), Figures 1a and 1b illustrate the output directional distance function for the direction vector $\mathbf{g}=\left(0, g_{y},-g_{b}\right)$. In the

\footnotetext{
${ }^{2}$ In the specific context of this study, weak disposability of good and bad outputs refers to the analyzed output quantities (production and number of work accidents). Nonetheless, our analysis can be extended by exploring alternative scenarios that include in the model investments in accident prevention actions (e.g., training and equipment) as well as post-accident costs (e.g., workers' medical treatment, operational losses related to materials or equipment, or working hours lost). This type of analysis may help to unveil whether the economic value of specific investments aimed at reducing work accidents—in terms of both lower accident rates and territorial economic activity — outweigh the economic cost of work accidents. We are thankful to one of the reviewers for underlining this relevant point. This alternative analysis is beyond the scope of this study and obviously constitutes a promising line for future research.
} 
hypothetical example, we use a technology in which one fixed input (x) produces one good output (y) and one bad output (b), and we present the case of four fictitious units (A, B, C, and D) in the hyperplane by points $(x, y, b) \in \mathbb{R}_{+}^{3}$, where $A=(1,2,1), B=(1,5,4), C=(1,4,6)$, and $D=(1,3,4)$. The technology bundle is represented by all points and surfaces bounded by the planes $(0, A, B),(0, B$, C), and $(0, \mathrm{C},(1,0,6))$ (note that the point $(1,0,6)$ is a feasible point of the frontier).

--- Insert Figures 1a and 1b about here ---

By using equation (1) to compute the efficiency scores on the data we note that units A, B and C are efficient $\left(\theta_{i}=0\right)$, while unit $\mathrm{D}$ is inefficient. To reach the technology frontier, unit $\mathrm{D}$ can follow different strategies which exclusively depend on their priorities. In this example we present two possible solutions that correspond to two different scenarios.

First, unit D can expand both the desirable and undesirable outputs using the same input level (point $\mathrm{D}(\mathrm{h})$ in Figures 1a and 1b). This solution is the outcome of the standard DEA model (section 3.1) that does not differentiate the production of good and bad outputs. In this case, the technology assumes that units operate in an unregulated setting (e.g., without OHS system) in which the production of bad output is costless (the input level is unchanged). This way, unit D can freely expand both its good and bad output without any cost (e.g., safety sanctions).

Second, the model proposed in this study (equation (1)) assumes that unit D is inefficient because it can simultaneously increase its good output and decrease its bad output. ${ }^{3}$ Therefore, our estimation strategy offers a more balanced approach in which economic and work safety objectives coexist. The result obtained from equation (1) (Appendix A) indicates that for unit $\mathrm{D} \theta_{i}=0.2857$ and the output

\footnotetext{
${ }^{3}$ Keep in mind that equation (1) can be modified to model other sources of inefficiency. For example, unit D can reach the frontier by expanding its good output without increasing its level of bad output (i.e., producing the same level of good output than unit B). This approach assumes that inefficient units can expand their good output without producing bad output. For the purposes of our work, this unrealistic strategy is inconsistent with the notion that economic activity and work accidents are inherently connected (see, e.g., Fernández-Muñiz et al. 2018, Lafuente and Abad 2018, Lafuente and Daza 2020). Also, efficiency can be linked to the minimization of the bad output and the production of the same level of good output, while keeping the input fixed. This latter strategy assumes that the production of good output is unaffected by reductions in the bad output. In the context of our study, this would imply that OHS monitoring and disciplinary controls (inspections and economic sanctions) do not affect businesses' operations.
} 
directional distance function scales in the counter-clockwise direction of increase in good output and reduction in bad output to the point $\mathrm{D}^{*}$ on the frontier (Figures 1a and 1b). At point $\mathrm{D}^{*}$ the unit $\mathrm{D}$ is efficient and the output vector is $\left(y+\theta g_{y}, b-\theta g_{b}\right)$, where $\theta=\vec{D}_{O}\left(y, b ; g_{y},-g_{b}\right), \theta g_{y}$ is the estimated increase in the good output (28.57\%), and $\theta g_{b}$ represents the estimated decrease in bad outputs (28.57\%). Numerically, the result indicates that the fictitious unit D should simultaneously expand its good output by $3 \times 0.2857=0.86$ and reduce its bad output by $4 \times 0.2857=1.14$ to operate efficiently .

Note that in this study all linear programs—based on equation (1)—are estimated using GAMS@ software. For illustrative purposes, the GAMS $($ C code employed to compute the efficiency scores of the units included in this example is presented in Appendix A.

In sum, various reasons lead us to believe that the proposed directional distance function approach constitutes a valid tool to model the joint production of desirable and undesirable outputs. Contrary to parametric methods (e.g., stochastic frontier or regression models), the DDF function is particularly appealing to model the territories’ production technology by allowing for multiple (and competing) outputs to be pursued (Färe et al. 2007). Additionally, the proposed DDF model does not impose any assumption on the functional distribution. This is especially relevant for the purposes of this study. A flexible function, such as the proposed DDF, is ideal in cases where information about the true technology is limited (Murty and Russell 2018). In our case, instead of imposing theoretical functional forms with necessary conditions, the flexible nature of the proposed DDF model has the advantages of determining the properties of the technology based on the data patterns, and of allowing an asymmetric treatment of the analyzed outputs in which the efficiency trajectory of provinces is conditional on the their inputs. Therefore, the specified technology takes into consideration the distinctive properties of a production function with negative externalities which, in turn, permits the direct assessment of the role of public safety controls on the efficiency level of Spanish provinces.

\section{Data and variable definition}

The data used in this study come from two sources, and include information for the 50 Spanish provinces during 2003-2012. First, data on macroeconomic figures related to employment (number of 
workers), number of businesses and territorial performance—Gross Domestic Product (GDP)

expressed at constant 2011 prices—was collected from the Spanish Institute of Statistics

(www.ine.es). Second, data on the number of work accidents reported by organizations were collected from the databases of the General Office of Statistics of the Spanish Ministry of Employment and Social Security. Third, information on OHS interventions at the province level was gathered from the Annual Report on Occupational Health and Safety generated by the Spanish Ministry of Employment and Social Security. These reports contain specific data on the number of safety inspections carried out by the public administration at province level as well as on the economic sanctions imposed to businesses due to OHS violations. The final dataset contains information for the 50 Spanish provinces (NUTS-3) for the period 2003-2012, that is, 500 province-year observations.

In the context of this study, we propose that provinces employ resources (labor and economic agents) to generate one economic output (GDP), and that policy makers make use of OHS disciplinary controls (safety inspections and economic sanctions) to mitigate the unintended consequences of economic activity, that is, work accidents. Table 1 presents the mean values for the variables included in the input-output set for the analyzed period.

--- Insert Table 1 about here ---

In the proposed empirical application (equation (1)) the input vector (x) includes resources linked to territorial economic activity: (x1) number of workers aged between 18 and 65 years old and (x2) number of businesses. Additionally, we introduce two inputs strictly related to OHS control mechanisms used by the public administration to decrease work accidents (bad output): (x3) number of safety inspections (which can be seen as a control or monitoring mechanism), and (x4) safety sanctions imposed to businesses expressed in millions of constant 2011 euro (which can be considered a disciplinary mechanism).

In our model specification two outputs are jointly produced: (y) one desirable output, GDP expressed in millions of constant 2011 euro, and (b) one undesirable output, number of work accidents reported by firms. Territories inevitably produce these outputs simultaneously. Additional descriptive 
statistics presented in Figure 2 show that the rate of work accidents remained relatively stable in the growth period (2003-2007). On contrary, we observe a drastic fall in the rate of work accident during the period of economic slowdown that hit Spain and most economies around the globe. Also, the observed evolution for the work accident rate and the GDP per capita follow a similar pattern over the analyzed period $($ Pearson correlation $=0.6710, p$-value $<0.001$ ), which is in line with prior studies emphasizing a positive relationship between these two variables in Spain (De la Fuente et al. 2014, Fernández-Muñiz et al. 2018).

--- Insert Figure 2 about here ---

\section{Results}

The findings of the empirical analysis are presented in this section. Prior to reporting the efficiency results based on equation (1) we ran an additional model specification to corroborate the relevance of OHS policy actions by public administrations (inputs) in explaining the efficiency level of Spanish provinces. More concretely, we employ equation (1) to re-compute the efficiency level of Spanish provinces (see Appendix B). This alternative model excludes the OHS inputs (x3: safety inspections, $\mathrm{x} 4$ : safety sanctions) from the technology function and proposes that the good (GDP) and the bad (work accidents) outputs are produced by labor and businesses. The result of the Wilcoxon signed-rank test $(Z$-value $=14.578, p$-value $<0.001)$ confirms that this alternative specification produces efficiency results significantly different at $1 \%$ level, relative to estimates obtained from the full model that includes safety inspections and economic sanctions when analyzing the simultaneous production of desirable (GDP) and undesirable (work accidents) outputs. Consequently, in what follows the efficiency results for the full model including OHS policy controls are analyzed.

\subsection{Efficiency analysis}

Summary statistics of the estimated efficiency scores are presented in Table 2, while Appendix C shows, for each province, the average efficiency results for the full period (2003-2012), the growth period (2003-2007) and the slowdown period (2008-2012). 
Additionally, we are aware of the importance of connecting theory to the study results. Therefore, for illustrative purposes, Appendix D displays the empirically constructed technology function for a selected year (2012) along with scatterplots of GDP and work accidents (Figures A1 and A2). The computational details as well as the description of the results of this supplementary analysis are presented in Appendix D. The findings presented in this Appendix constitute the empirical representation of Figures 1a and 1b.

Overall, the results in Table 2 and Figure 3 show that, on average and for the full period, Spanish provinces can improve their efficiency and reach the technology frontier by simultaneously expanding their GDP and contacting their work accidents 9.05\%, while keeping their inputs fixed. Additionally, from the results in Figure 3 one can notice different temporal patterns in the efficiency level of Spanish provinces. In the period of economic growth (2003-2007) efficiency gradually deteriorated to the highest level of $12.07 \%$ in 2008 .

The second half of the studied period (2008-2012) is dominated by the economic meltdown. After peaking in 2008, the average inefficiency of Spanish provinces generally decreased during this period to the level of $8.54 \%$ in 2012. This result indicates that, on average and holding the input levels fixed, Spanish provinces can employ their economic (labor and business stock) and OHS (inspections and economic sanctions) inputs to simultaneously expand their GDP and contract their work accidents by 8.54\%. Although the efficiency improvement reported during the period of low economic growth, note that the average inefficiency between 2008 and 2012 (10.03\%) is significantly higher (Wilcoxon signed-rank test: Z-value $=-3.242, p$-value $=0.0012)$ than that observed in the period of economic growth (8.06\%) (Appendix C).

\footnotetext{
--- Insert Table 2 about here ---

--- Insert Figure 3 about here ---
}

Additionally, note that the 50 Spanish provinces are grouped in 17 Autonomous Communities. Table 3 presents additional aggregate statistics for the efficiency scores and the level of OHS inputs (safety inspections and economic sanctions) for the Autonomous Communities forming Spain. The 
results reveal some findings that are worth highlighting. First, it should be noted that, compared to average values for the growth period (2003-2007), efficiency deteriorated in 30 out of the 50 Spanish provinces during the period of economic slowdown (see Appendix C). During the 2008-2012 period, the provinces with the highest inefficiency level are Toledo in Castile La Mancha (average inefficiency $=26.30 \%$ ), Huelva in Andalusia (average inefficiency $=24.66 \%$ ), Las Palmas in Canary Islands (average inefficiency $=24.12 \%$ ), Pontevedra in Galicia (average inefficiency $=23.26 \%$ ), and Badajoz in Extremadura (average inefficiency $=22.25 \%$ ). Additionally, only five provinces are efficient in both sub-periods (growth and economic slowdown: Álava and Guipúzcoa (Basque Country), Madrid, Soria (Castile Leon), and Teruel (Aragon). These five provinces consistently shape the technology frontier in both periods.

--- Insert Table 3 about here ---

Second, at the Autonomous Community level we observe that, similar to figures reported by the EU (European Commission, 2013), the level of OHS policy controls dedicated to mitigate work accidents experienced a drastic fall during the period of economic slowdown (2008-2012), relative to the values observed between 2003 and 2007: the average number of safety inspections decreased $21.25 \%$, while the economic values of safety sanctions fell $25.81 \%$. The budget cuts were particularly severe in the Communities of Asturias, Catalonia, Madrid, and Murcia (Table 3). On contrary, the number of safety inspections increased in Castile La Mancha, Extremadura and La Rioja, while Extremadura and Aragon report an increase in OHS sanctions. Third, from Table 3 we observe an efficiency deterioration between the growth and slowdown period in ten out of the 17 Communities, and that the most inefficient regions during the 2008-2012 period are Extremadura (average inefficiency $=19.84 \%$ ), Balearic Islands (average inefficiency $=19.50 \%$ ) and Andalusia (average inefficiency $=17.73 \%$ ). To the contrary, the most efficient Autonomous Communities during the period of low economic growth are Madrid (fully efficient and positioned on the technology frontier), Navarra (average inefficiency $=0.08 \%$ ) and the Basque Country (average inefficiency $=0.74 \%$ ). 
Despite the significant budget cuts that translated into lower OHS policy controls and interventions, the high efficiency level for Madrid and Navarra in the period of economic growth as well as in the period of economic slowdown suggests that effective OHS policy is not necessarily linked to merely employing more OHS resources.

\subsection{Second stage: Efficiency patterns across different stages of the economic cycle}

The findings in section 5.1 lead us to conjecture whether the effects on efficiency of safety controls converge over time or, to the contrary, whether provinces show different efficiency paths according to the economic cycle. To test for the presence of persistence across the analyzed periods we estimated the probability density function of the efficiency scores through stochastic Kernel density functions (the function used to compute the density estimates is the Epanechnikov Kernel). This way we can map the distribution of the provinces' efficiency estimated for the period of economic growth (2003-2007) and the period of economic slowdown (2008-2012), and describe transitions between the distributions yielded in each period.

Therefore, this analysis permits to test the effect of changes in the economic cycle over the efficiency level of Spanish provinces. Also, the two-sample Kolmogorov-Smirnov test for equality of distribution functions was used to detect differences in the distribution of the two sets of efficiency scores. The result of the test (Combined value $=0.1560$ and $p$-value $=0.003$ ) confirms that the distribution of efficiency in the growth period is significantly different than that estimated during the period of economic slowdown (see Appendix E).

Figure 4 reports the stochastic Kernels for the efficiency scores in the two periods. To ease the interpretation of the results, note that efficiency persistence would emerge from an overwhelming concentration of the probability density function along the positive sloped diagonal. In this case, persistence — graphically evident in probability concentration along the 45-degree line in Figure 4would suggest that the effect of changes in the state of the economy (growth or slowdown) over territorial efficiency is homogeneous across Spanish provinces. 
The findings in Figure 4 indicate that persistence does not prevail as the probability mass of inefficiency tends to abandon the positive sloped diagonal during the crisis period.

Examples of provinces that abandoned the persistence area during the crisis period are Burgos (Castile Leon), Jaen (Andalusia), Seville (Andalusia), Coruña (Galicia), Lugo (Galicia), Ourense (Galicia), Ciudad Real (Castile La Mancha), and Guadalajara (Castile La Mancha) (see Appendix C). The efficiency level in these provinces (Group A) experienced a major decline between the growth period (average inefficiency level $=5.26 \%$ ) and the period of economic slowdown (average inefficiency level $=14.66 \%$ ). Also, these provinces report a below-average reduction in both OHS monitoring (inspections) and disciplinary (economic sanctions) controls between the growth and crisis period (variation in inspections $=-4.62 \%$, variation in safety economic sanctions $=-9.52 \%$ ), compared to the values reported for the rest of Spain (variation in inspections $=-23.43 \%$, variation in safety economic sanctions $=-27.26 \%$ ). However, the less-than-proportionate reduction in OHS controls did not materialize in superior OHS performance, in terms of lower work accident rates. The reduction in the rate of work accidents in these provinces (28.33\%) is ten percentage points below the average reduction observed in the rest of Spanish provinces (38.29\%). Thus, these provinces constitute an example of territories that make an inefficient use of their available OHS policy controls.

Additionally, there are two groups of provinces that show temporal persistence and their efficiency mostly concentrate around the sloped diagonal. On the one hand, we observe a group of 18 provinces (Group B)—with an inefficiency level below 10\%—whose inefficiency level remained mostly unchanged between the growth (average inefficiency $=2.32 \%$ ) and slowdown (average inefficiency $=2.37 \%$ ) period. These provinces are located in the Communities of Aragon (Huesca, Teruel and Zaragoza), Asturias, Basque Country (Álava and Guipúzcoa), Cantabria, Castile Leon (Salamanca, Segovia, Soria and Zamora), Catalonia (Girona, Lleida and Tarragona), Madrid, Navarra, and Valencia (Alicante and Castellon). On the other hand, we identified a group of highly inefficient provinces (Group C) in both the growth (average inefficiency $=20.77 \%$ ) and the economic slowdown (average inefficiency $=21.86 \%$ ) periods. These provinces are located in the Communities of 
Andalusia (Almeria and Huelva), Canary Islands (Las Palmas and Sta. Cruz Tenerife), and Castile La Mancha (Toledo).

Having corroborated that the analyzed components of the safety function-i.e., inspections and economic sanctions_-explain efficiency differences across provinces, we explore an alternative explanation for the observed variations in efficiency. Economists (e.g., Arrow et al. 1996, p. 222) and operations management researchers (e.g., Brown 1996, p. 168) have recommended the periodical assessment of OHS regulations. However, in our case such analysis would be trivial because OHS policy controls are governed by a uniform regulation that did not experience any significant modification during the study period (see Section 2). Therefore, we turn our attention to the configuration of the local industrial fabric. Specifically, and following prior work in operations management and safety management highlighting that some industries are more accident prone than others (e.g., Lo et al. 2014, Sedano-de la Fuente et al. 2014, Wiengarten et al. 2017, Lafuente and Abad 2018), we conducted a supplementary analysis focused on the potential impact of the local industry mix on the rate of work accidents.

The results of this robustness check (see Appendix F) suggest that work accident rates are higher in provinces where the construction sector is more important (compared to service sectors). The consequences of the economic crisis that hit Spain after 2008 were especially evident in the construction sector, and a further scrutiny of the data reveals that the average weight of the construction sector in the provinces' industry mix fell 9.57\% between 2008 and 2012, a rate that almost doubled the overall change in the average number of establishments in Spain $(-5.53 \%)$. Nevertheless, if we look at the result for the provinces included in the Group A we observe that the fall in the proportion of construction establishments (-3.08\%) between 2008 and 2012 is lower than the fall in safety interventions (variation in inspections $=-4.62 \%$, variation in economic sanctions $=-$ 9.52\%). Also, the reduction in the proportion of construction establishments in this group is lower than that found in the group of consistently efficient (Group B) and consistently inefficient (Group C) provinces ( $-5.31 \%$ and $-6.35 \%$, respectively). Although the data does not permit the direct analysis of the organization of safety inspections, it is plausible to suppose that the increased inefficiency reported for provinces in Group A may be partially explained by a more than proportionate decrease in safety 
interventions, a fact that could have negatively affected inspections in more accident prone industries (construction) and, consequently, their efficiency level.

The objective of this robustness check was to show that—besides production aspects explicitly related to the exploitation of economic and OHS inputs-territories’ efficiency may be conditional on factors related to the configuration of the local industry mix ${ }^{4}$. The core finding of this exercise further validates the interpretations presented in Sections 5.1 and 5.2, that is, the components of the safety function (inspections and economic sanctions) are critical in shaping territorial efficiency. Also, the results obtained in this section indicate that, after the change in the state of the economy in 2008, Spanish regions introduced modifications in their OHS policies which had a heterogeneous impact on their OHS controls and, consequently, on their efficiency level.

\section{Discussion}

What is the contribution of our study relative to the findings obtained in the recent literature analyzing work safety and OHS policies at the territorial level? First, to the best of our knowledge, we are the first to model work accidents as an unintended outcome of economic activity in a model of territorial productivity. In our approach to productivity, we propose that territories pursue multiple objectives related to economic (GDP) and OHS (work accidents) outcomes, and that these desirable and undesirable outputs are simultaneously produced. We present novel empirical evidence on territorial efficiency suggesting that a model that incorporates the undesirable labor-related outputs (work accidents) of economic activity (GDP) in the territories' production function offers robust estimations that may contribute to better understand the driving forces of territorial productivity.

Second, and in a closely related manner, we pay particular attention to the role of occupational health and safety (OHS) policy controls. Prior research underlines the relevance of the state of the economy (growth or recession) and factor accumulation (primarily labor) for explaining the

\footnotetext{
${ }^{4}$ Underlying the modeled technology in equation (2) is the presumption that GDP and work accidents are produced by economic (businesses and labor) and OHS (inspections and economic sanctions) inputs. To accurately capture other (industry-specific) effects, a production analysis considering the number of firms (or establishments) in different industries should include both policies that promote the creation of businesses in specific industries and the distribution of OHS interventions by industry. Our analysis focuses on the role of OHS interventions on territorial efficiency. The industry-specific productivity analysis is beyond the scope of this paper and, therefore, is an issue that can be addressed in future work.
} 
longitudinal differences in the rate of work accidents across territories and across time (e.g., Davies et al. 2009, Asfaw et al. 2011, Boone et al. 2011, Song et al. 2011). By regressing work accident rates against economic activity variables, studies in this tradition assume that the resources and the institutional setting governing work safety are homogeneous across territories, thus ignoring the direct effect of OHS interventions over both the economic activity and the rate of work accidents at the territorial level.

In this study we proposed that, besides economic factors directly connected to territorial economic activity and indirectly linked to work accidents rates, OHS policy controls are critical elements of territories’ production function that play a decisive role in shaping their efficiency level. In our interpretation, OHS policy controls are conducive to efficiency by triggering the beneficial effects of different types of interventions that we link to safety inspections and the economic sanctions associated with safety violations. Our results pointing to higher inefficiency levels in Spanish provinces that experienced severe cuts in OHS policy controls are in line with this argument. Nevertheless, results suggest that effective OHS policy is not necessarily linked to merely deploying more safety-related resources. Although the data do not permit a more in-depth scrutiny, both the dissimilar evolution of efficiency scores (Figure 4) and the heterogeneous fall in safety inputs observed for most Autonomous Communities (Table 3) offer a descriptive indication that Autonomous Communities follow different approaches when it comes to allocate OHS resources.

At the territorial level, both economic activity (GDP) and work accident rates are the observable outcomes of various efforts by economic agents and policy makers, and from our results we conclude that policies oriented to promote the productive practices of the stakeholders that coexist in the local territory (i.e., businesses, employees) should accommodate OHS policy objectives if the process that generates territorial productivity is to work.

\section{Conclusions, implications and future research lines}

\subsection{Concluding remarks}

This study has produced novel economic evidence on the importance of public work safety controls for territorial productivity. More concretely, we scrutinized the connection between the 
economic function—characterized by the exploitation of local resources (labor and businesses) to produce GDP — and the safety function—characterized by the use of OHS policy controls to mitigate work accidents - and how these two functions interact to shape the production function of territories. We argue that work accidents are undesirable outcomes of economic activity, and the proposed technology function incorporates the joint production of desirable (GDP) and undesirable (work accidents) outputs. Also, the modeled technology allows territories to employ OHS policy controlswhich we link to safety inspections and economic sanctions — to mitigate work accidents.

Overall, the results are consistent with prior research emphasizing the strong correlation between economic outcomes and work accident rates in different settings (see, e.g., Boone and van Ours (2006) for 16 OECD countries, Davies et al. (2009) for the UK, Asfaw et al. (2011) for the US, and De la Fuente et al. (2014) and Fernández-Muñiz et al. (2018) for Spain). Nevertheless, at the province level the results indicate that the changes in OHS interventions introduced by Spanish policy makers after the change in the state of the economy in 2008 had a heterogeneous impact on territorial efficiency. Efficiency declines were not more pronounced in provinces that introduced drastic cuts in OHS policy controls (i.e., safety inspections and sanctions for safety violations). Results suggest that effective OHS policy is not implicitly linked to the mere deployment of more OHS policy controls.

\subsection{Policy implications}

What are the policy implications that can be extracted from the proposed analysis of the economic and safety functions that shape territorial efficiency? In an increasingly complex economic setting, policy makers grapple with competing demands including, among others, the coordinated design of policies targeting societal objectives (e.g., reduce work accidents) and meeting collective goals that can improve the economic condition of the population (e.g., enhance the local GDP). The policy implications discussed in this section emerge from the results of the study and are strictly connected to our research questions.

The reported fall in occupational accidents after 2008 is unquestionably good news; however, the analysis of both the underlying causes of such reduction and the evolution of OHS policy controls in Spain reveals a less positive case. The low or null correlation between work accident rates and 
economic outcomes constitutes an observable consequence of the quality of an OHS system. At the territorial level, this logic suggests that policy decisions affecting the control mechanisms that govern territories' OHS system should be unconnected both to the state of the economy and to changes in the economic cycle. Reforms in the Spain's OHS system sought the harmonization with EU regulation, as well as a greater compliance with OHS norms via enhanced monitoring over businesses and the simplification of OHS procedures for SMEs. Nevertheless, the evidence presented in this study suggests that the operational changes in the OHS controls during the analyzed period are negatively affecting the effectiveness of the Spain's OHS system and, ultimately, the efficiency level of Spanish provinces. This result suggests that the safety function-i.e., the rules governing territories’ OHS system — contributes to explain efficiency differences across territories, which is also connected to our first research question ('are OHS systems symbolic (sterile) policy instruments unconnected to territories' production function and, consequently, to their efficiency level?').

Therefore, we suggest that policy makers should devote more attention to the characteristics of more 'accident-prone' businesses in order to promote OHS interventions that enhance the efficient use of available OHS resources. For example, by analyzing the statistics available from the Spanish Occupational Health and Safety Institute (INSHT 2015, pp. 57-66), OHS policy makers can deduce the profile of businesses with a greater probability to report work accidents: small firms mostly operating in extractive and construction sectors, employing temporary workers aged below 25 years (if the focus is the total work accident rate) or aged above 50 years (if the focus is the rate of fatalities). To the best of our knowledge, Spain's inspectorate has no uniform protocol—at the Autonomous Community level — to select businesses for safety inspections. But, in our view this type of valuable information may usefully be made more central to design more effective OHS policies, such as those linked to the allocation of resources (inspectors) aimed at improving the efficiency of OHS controls.

Additionally, the findings suggest that a policy of complacency—characterized by important cuts in OHS controls at the territorial level—is infiltrating into the OHS system across many Spanish provinces. This is especially evident in a group of provinces whose OHS decision-making processes led to drastic cuts in safety controls and, consequently, to a deterioration of their efficiency level. In the short-term, this policy translates into a weaker OHS system, thus increasing the high positive 
correlation between economic activity and work accidents. OHS policies would become sterile if those agents commanding the implementation of safety controls navigate in uncertain contexts that undermine the effective exploitation of their resources and knowledge. In the long-term, the pervasiveness of this complacency policy can make territories to fall into a 'catch 22' loop in which ineffective OHS controls perpetuate the pro-cyclical relationship between work accidents and the state of the economy.

In connection with our second research question ('should OHS policy become the norm given that territories can achieve better OHS results by simply deploying more resources to OHS preventive interventions?'), our results show that the mere deployment of OHS resources is not enough to successfully enhance territories’ work safety metrics. Therefore, the prescription for policy makers is to prioritize the development of OHS policies that promote the efficient allocation of resources and the implementation of safety controls, regardless of the characteristics of the economic cycle. In this sense, efficient OHS policy controls-i.e., inspections, economic sanctions, and efficient selection of inspected businesses — jointly with the development of instruments that encourage a greater involvement of businesses in OHS actions - such as fiscal incentives or lower insurance premiums for businesses with highly positive OHS records or the ‘bonus malus' system adopted by France and Germany (Elsler et al. 2010, Fernández-Muñiz et al. 2018)—may prove themselves effective actions in promoting safer workplaces (Arocena and Nuñez 2009).

\subsection{Directions for future research}

As with any study, the findings presented in this work are open to future verification. In this sense, it would be valuable to extend the analysis in various directions. First, and similar to other studies dealing with the relationship between economic outcomes and work accident rates (see, e.g., Davies et al. 2009, Asfaw et al. 2011, Fernández-Muñiz et al. 2018, Lafuente and Daza 2020), the data do not allow a direct analysis of the decision-making process underlying the implementation of specific OHS policy controls. We offer various interpretations of how work-accident mitigating actions are driven by different factors (economic activity, inspections and economic sanctions); however, we do not evaluate how OHS resources (e.g., inspectors) are allocated among businesses or 
industries, nor do we assess the responsiveness of businesses to both OHS controls (inspections and economic sanctions) and the unintended consequences of their economic activity (work accidents). Further research can address this issue by analyzing the response to incentives created by the public administration. This type of analysis can contribute to determine the conditions under which businesses implement OHS investments and adopt greater internal safety controls.

Second, and in a closely related manner, differences in work accidents across territories may well result from discrepancies in the organization as well as in the outcomes of inspections. These aspects were not addressed in this study due to lack of data. Because the Spanish inspectorate promotes both advisory and monitoring interventions, future studies should extend our analysis—-focused on monitoring and disciplinary interventions—by adopting a more pluralistic approach to the safety function that takes into consideration the specific effect of safety inspectors' advice. Also, future research should evaluate the industry-specific effects of the advisory and monitoring tasks of the safety function. From a policy perspective, these analyses would shed light on the effect of advisory interventions on territorial productivity, and would contribute to verify whether the effect of advisory and monitoring interventions is heterogeneous across industries.

Finally, and following the debate on the role of OHS regulation presented by Piore and Schrank (2018), the proposed analysis would gain richness if future comparative studies analyze the effectiveness of OHS interventions, distinguishing territories where OHS regulation is similar to the US model—i.e., high organizational decentralization, specialized safety inspectors and deterrenceoriented penalization - from territories whose OHS regulation is closer to the generalist, complianceoriented Franco-Latin model.

Acknowledgements: This research was supported by the Spanish Ministry of Economy, Industry and Competitiveness (grant number: ECO2017-86305-C4-2-R).

\section{References}

Acemoglu, D., Aghion, P., Bursztyn, L., Hemous, D., 2012. The Environment and Directed Technical Change. Am. Econ. Rev. 102(1), 131-166. 
Acs, Z.J., Autio, E., Szerb, L., 2014. National systems of entrepreneurship: Measurement issues and policy implications. Res. Policy 43(3), 476-494.

Arocena, P., Nuñez, I., 2009. The effect of occupational safety legislation in preventing accidents at work: traditional versus advanced manufacturing industries. Environ. Plann. C 27, 159-174.

Arrow, K.J., Cropper, M.L., Eads, G.C., Hahn, R.W., Lave, L.B., Noll, R.G., Portney, P.R., Russell, M., Schmalensee, R., Smith, V.K., Stavins, R.N., 1996. Is there a role for benefit-cost analysis in environmental, health, and safety regulation? Science 272(5259), 221-222.

Asfaw, A., Pana-Cryan, R., Rosa, R., 2011. The business cycle and the incidence of workplace injuries: evidence for the U.S.A. J. Safety Res. 42, 1-8.

Barros, C.P., Managi, S., Matousek, R., 2012. The technical efficiency of the Japanese banks: nonradial directional performance measurement with undesirable output. Omega 40(1), 1-8.

Boone, J., van Ours, J.C., 2006. Are recessions good for workplace safety? J. Health Econ. 25, 10691093.

Boone, J., van Ours, J.C., Wuellrich, J.P., Zweimüller, J., 2011. Recessions are bad for workplace safety. J. Health Econ. 30, 764-773.

Brown, K.A., 1996. Workplace safety: a call for research. J. Oper. Manag. 14(2), 157-171.

Caselli, F., Coleman, W.J., 2006. The World Technology Frontier. Am. Econ. Rev. 96(3), 499-522.

Chambers, R.G., Chung, Y., Färe, R., 1996. Benefit and distance functions. J. Econ. Theory 70(2), 407-419.

Cherchye, L., Moesen, W., Van Puyenbroeck, T., 2004. Legitimately diverse, yet comparable: On synthesizing social inclusion performance in the EU. JCMS-J. Common Mark. S. 42, 919-955.

Chung, Y., Färe, R., Grosskopf, S., 1997. Productivity and undesirable outputs: A directional distance function approach. J. Environ. Manag. 51, 229-240.

Cook, W.D., Seiford, L.M., 2009. Data envelopment analysis (DEA)—thirty years on. Eur. J. Oper. Res. 192(1), 1-17.

Cooper, W.W., Seiford, L.M., Zhu, J., 2011. Handbook on data envelopment analysis, 2nd edition. Springer, New York. 
Davies, R., Jones, P., Nuñez, I., 2009. The impact of the business cycle on occupational injuries in the UK. Soc. Sci. Med. 69, 178-182.

De la Fuente, V.S., López, M.A.C., González, I.F., Alcántara, O.J.G., Ritzel, D.O., 2014. The impact of the economic crisis on occupational injuries. J. Safety Res. 48, 77-85.

Despotis, D.K., 2005. A reassessment of the human development index via data envelopment analysis. J. Oper. Res. Soc. 56, 469-480.

Elsler, D., Treutlein, D., Rydlewska, I., Frusteri, L., Krüger, H., Veerman, T., Eeckelaert, L., Roskams, N., Van Den Broek, K., Taylor, T., 2010. A review of case studies evaluating economic incentives to promote occupational safety and health. Scand. J. Work Env. Hea. 36(4), 289-298.

European Agency for Safety and Health at Work, 2013. EU-OSHA Priorities for occupational safety and health research in Europe: 2013-2020. Luxembourg.

European Commission, 2007. Improving quality and productivity at work: Community strategy 20072012 on health and safety at work. Communication from the Commission to the European Parliament, the Council, the European Economic and Social Committee and the Committee of the Regions, COM (2007) 62.

European Commission, 2013. Thematic Day. Investment in Health and Safety: Economic Slowdown vs. Decent Work. 65th meeting of Senior Labour Inspectors Committee (SLIC), Vilnius, Lithuania (November 14th 2013).

European Commission, 2014. EU Strategic Framework on Health and Safety at Work 2014-2020. Communication from the Commission to the European Parliament, the Council, the European Economic and Social Committee and the Committee of the Regions, COM (2014) 332.

Epure, M., Lafuente, E., 2015. Monitoring bank performance in the presence of risk. J. Prod. Anal. 44(3), 265-281.

Färe, R., Grosskopf, S., Norris, M., Zhang, Z., 1994. Productivity growth, technical progress, and efficiency change in industrialized countries. Am. Econ. Rev. 84(1), 66-81.

Färe, R., Grosskopf, S., Hernandez-Sancho, F., 2004. Environmental performance: An index number approach. Resour. Energy Econ. 26(4), 343-352. 
Färe, R., Grosskopf, S., Lovell, C.A.K., Pasurka, C., 1989. Multilateral productivity comparisons when some outputs are undesirable: a nonparametric approach. Rev. Econ. Stat. 71(1), 90-98.

Färe, R., Grosskopf, S., Pasurka, C., 2007. Environmental production functions and environmental directional distance functions. Energy 32(7), 1055-1066.

Fernández-Muñiz, B., Montes-Peón, J.M., Vázquez-Ordás, C.J., 2018. Occupational accidents and the economic cycle in Spain 1994-2014. Safety Sci. 106, 273-284.

Gerdtham, U.G., Ruhm, C.J., 2006. Deaths rise in good economic times: evidence from the OECD. Econ. Hum. Biol. 4, 298-316.

Grifell-Tatjé, E., Lovell, C.A.K., 2015. Productivity Accounting: The Economics of Business Performance. Cambridge University Press, New York.

INSHT, 2015. Informe sobre el estado de la seguridad y salud laboral en España: 2014. INSHT Publications, Madrid.

Karagiannis, G., Lovell, C.A.K., 2016. Productivity measurement in radial DEA models with a single constant input. Eur. J. Oper. Res. 251(1), 323-328.

Kossoris, M., 1938. Industrial injuries and the business cycle. Monthly Labor Review, 579-594.

Kumar, S., 2006. Environmentally sensitive productivity growth: A global analysis using MalmquistLuenberger index. Ecological Economics 56(2), 280-293.

Kumar, S., Russell, R.R., 2002. Technological change, technological catch-up, and capital deepening: relative contributions to growth and convergence. Am. Econ. Rev. 92(3), 527-548.

Kuosmanen, T., 2005. Weak disposability in nonparametric productivity analysis with undesirable outputs. Am. J. Agr. Econ. 87(4), 1077-1082.

Lafuente, E., Abad, J., 2018. Analysis of the relationship between the adoption of the OHSAS 18001 and business performance in different organizational contexts. Safety Sci. 103, 12-22.

Lafuente, E., Acs, Z.J., Sanders, M., Szerb, L., 2019. The global technology frontier: productivity growth and the relevance of Kirznerian and Schumpeterian entrepreneurship. Small Bus. Econ., 55, $153-178$.

Lafuente, E., Daza, V., 2020. Work inspections as a control mechanism for mitigating work accidents in Europe. TEC Empresarial 14(1), 26-37. doi: https://doi.org/10.18845/te.v14i1.4953 
Lanoie, P., 1992. The impact of occupational safety and health regulation on the risk of workplace accidents. Quebec, 1983-87. J. Hum. Resour. 27, 643-660.

Liu, W.B., Zhang, D.Q., Meng, W., Li, X.X., Xu, F., 2011. A study of DEA models without explicit inputs. Omega 39, 472-480.

Lo, S-F., 2010. The differing capabilities to respond to the challenge of climate change across annex parties under the Kyoto protocol. Environ. Sci. Policy 13, 42-54.

Lo, C.K., Pagell, M., Fan, D., Wiengarten, F., Yeung, A.C., 2014. OHSAS 18001 certification and operating performance: The role of complexity and coupling. J. Oper. Manag. 32(5), 268-280.

Lovell, C.A.K., Pastor, J.T., 1999. Radial DEA models without inputs or without outputs. Eur. J. Oper. Res. 188(1), 46-51.

Lundvall, B-Å., 1992. National Systems of Innovations. Pinter Publishers, London, UK.

Mizobuchi, H., 2014. Measuring world better life frontier: A composite indicator for OECD better life index. Soc. Indic. Res. 118, 987-1007.

Murty, S., Russell, R.R., 2018. Modeling emission-generating technologies: reconciliation of axiomatic and by-production approaches. Emp. Econ. 54(1), 7-30.

Nichols, T., 1989. The business-cycle and industrial injuries in British manufacturing over a quarter of a century - continuities in industrial injury research. Sociol. Rev. 37(3), 538-550.

Odeck, J., 2006, Identifying traffic safety best practice: An application of DEA and Malmquist indices. Omega 34, 28-40.

Park, K.H., Weber, W.L., 2006. A note on efficiency and productivity growth in the Korean banking industry, 1992-2002. J. Bank. Financ. 30(8), 2371-2386.

Pham, M.D., Zelenyuk, V., 2018. Slack-based directional distance function in the presence of bad outputs: theory and application to Vietnamese banking. Emp. Econ. 54(1), 153-187.

Piore, M.J., Schrank, A., 2018. Root-cause regulation: Protecting work and workers in the twenty-first century. Harvard University Press, Cambridge, MA.

Podinovski, V.V., Kuosmanen, T., 2011. Modelling weak disposability in data envelopment analysis under relaxed convexity assumptions. Eur. J. Oper. Res. 211(3), 577-585. 
Ray, S.C., 2004. Data envelopment analysis: theory and techniques for economics and operations research. Cambridge University Press, New York.

Ray, S.C., Mukherjee, K., Venkatesh, A., 2018. Nonparametric measures of efficiency in the presence of undesirable outputs: a by-production approach. Emp. Econ. 54(1), 31-65.

Ruser, J., 1985. Workers’ compensation insurance, experience-rating, and occupational injuries. Rand J. Econ. 16, 487-503.

Ruser, J., Butler, R., 2009. The economics of occupational safety and health. Found. Trends Microecon. 5(5), 301-354.

Scott, R.W., 2001. Institutions and organizations, 2nd edition. Sage, Thousand Oaks, CA.

Sedano-de la Fuente, V.S., Camino-López, M.A., Fontaneda-González, I., González-Alcántara, O. .J, Ritzel, D.O., 2014. The impact of the economic crisis on occupational injuries. J. Safety Res. 48, 77-85.

Song, L., He, X., Li, C., 2011. Longitudinal relationship between economic development and occupational accidents in China. Accident Anal. Prev. 43(1), 82-86.

Spain, 1995. Ley 31/1995, de 8 de noviembre, de prevención de Riesgos Laborales. Boletín Oficial del Estado (Official Spanish Gazette), November 10th 1995, No. 269, p. 24292. Available at www.boe.es/buscar/act.php?id=BOE-A-1995-24292\&lang=en.

Spain, 1997. Ley 42/1997, de 14 de noviembre, Ordenadora de la Inspección de Trabajo y Seguridad Social. Boletín Oficial del Estado (Official Spanish Gazette), November 15th 1997, No. 274, p. 24432. Available at www.boe.es/buscar/doc.php?id=BOE-A-1997-24432

Spain, 2000a. Real Decreto 138/2000, de 16 de febrero, por el que se aprueba el Reglamento de Organización y Funcionamiento de la Inspección de Trabajo y Seguridad Social. Boletín Oficial del Estado (Official Spanish Gazette), February 16th 2000, No. 40, p. 3088. Available at www.boe.es/buscar/act.php?id=BOE-A-2000-3088

Spain, 2000b. Real Decreto Legislativo 5/2000, de 4 de agosto, por el que se aprueba el texto refundido de la Ley sobre Infracciones y Sanciones en el Orden Social. Boletín Oficial del Estado (Official Spanish Gazette), August 8th 2000, No. 189, p. 15060. Available at www.boe.es/buscar/doc.php?id=BOE-A-2000-15060 
Sueyoshi, T., Goto, M., 2011. Methodological comparison between two unified (operational and environmental) efficiency measurements for environmental assessment. Eur. J. Oper. Res. 210(3), 684-693.

Wiengarten, F., Fan, D., Lo, C.K., Pagell, M., 2017. The differing impacts of operational and financial slack on occupational safety in varying market conditions. J. Oper. Manag. 52, 30-45. 


\section{List of Figures}

Figure 1a. Output directional distance function with desirable and undesirable outputs (3D)

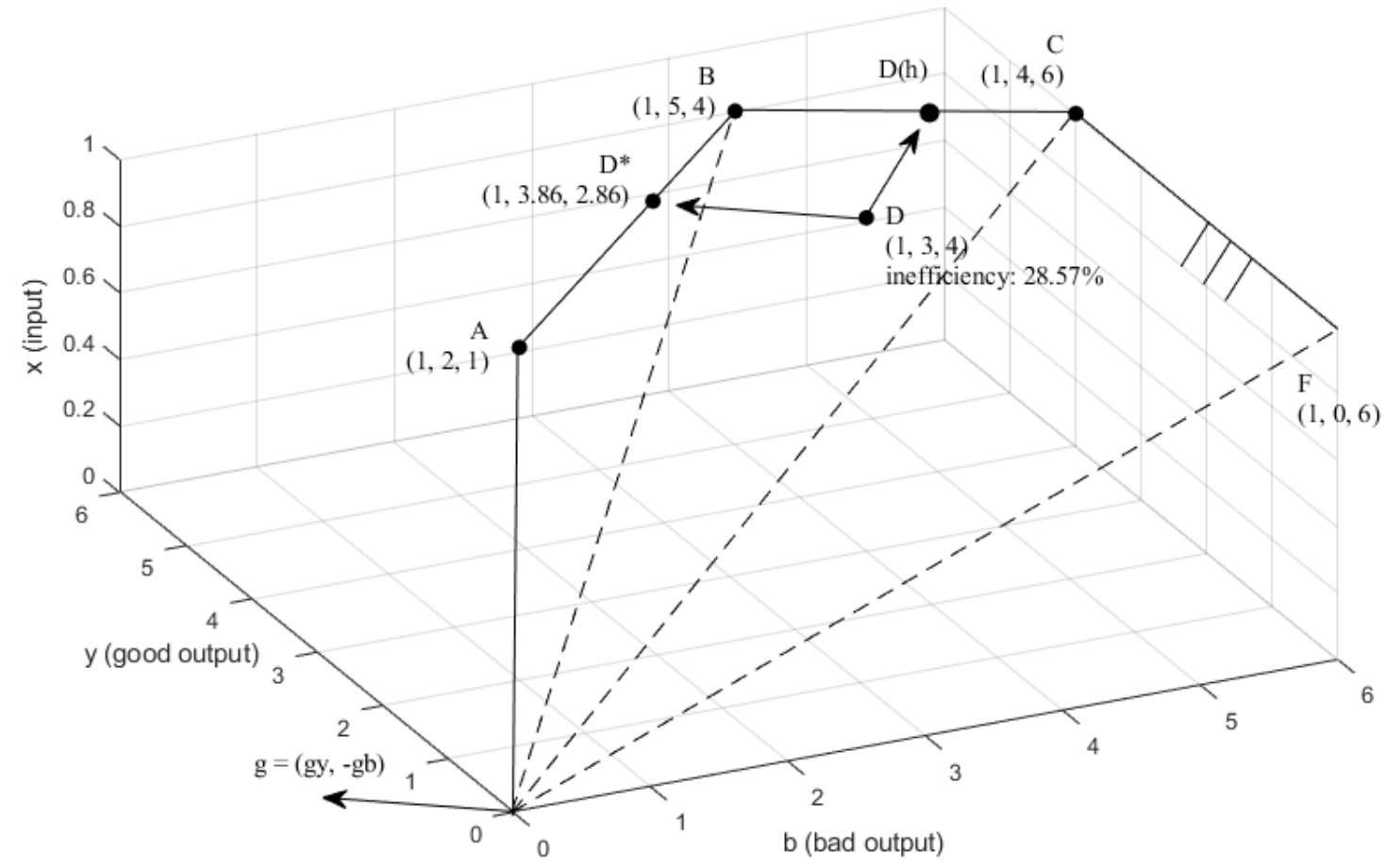

Source: Authors’ elaboration (efficiency scores were computed using GAMS@ (Appendix A), while the figure was created using Matlab)

Figure 1b. Output directional distance function with desirable and undesirable outputs (2D)

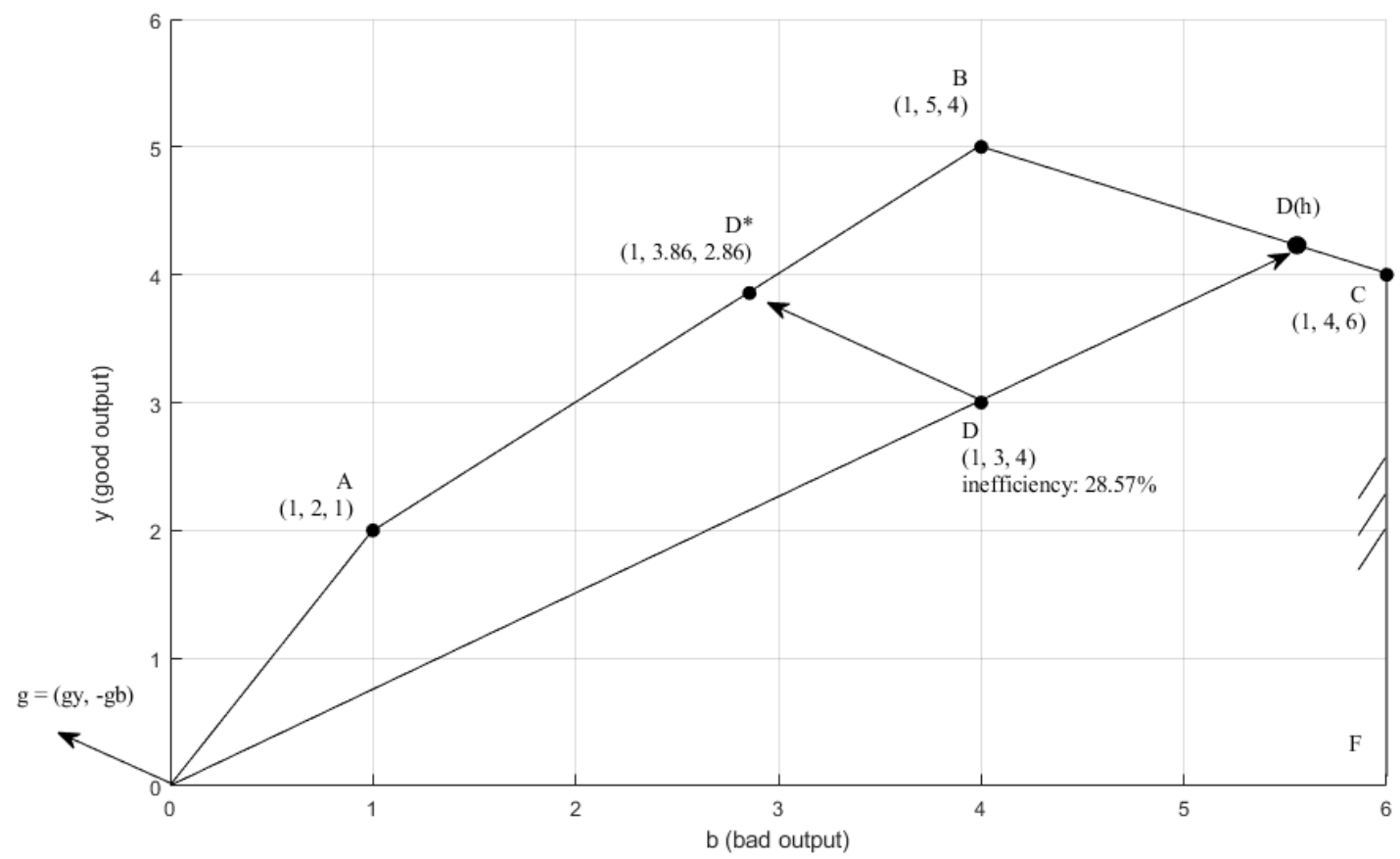

Source: Authors' elaboration (efficiency scores were computed using GAMS $\odot$ (Appendix A), while the figure was created using Matlab) 
Figure 2. Average variation in the GDP per capita (at constant 2011 prices) and work accident rates across Spanish provinces

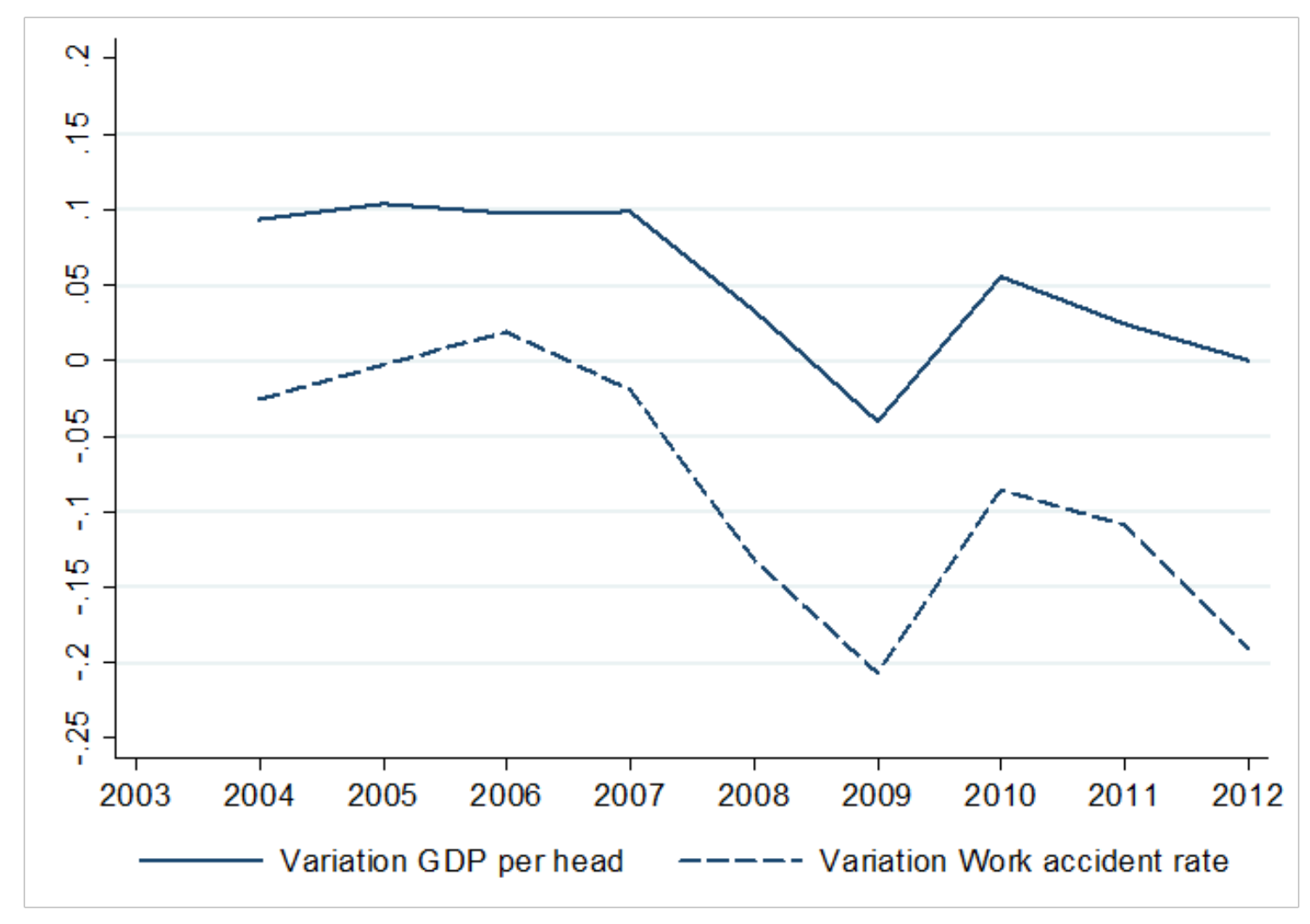

Figure 3. Efficiency scores: Average values between 2003 and 2012

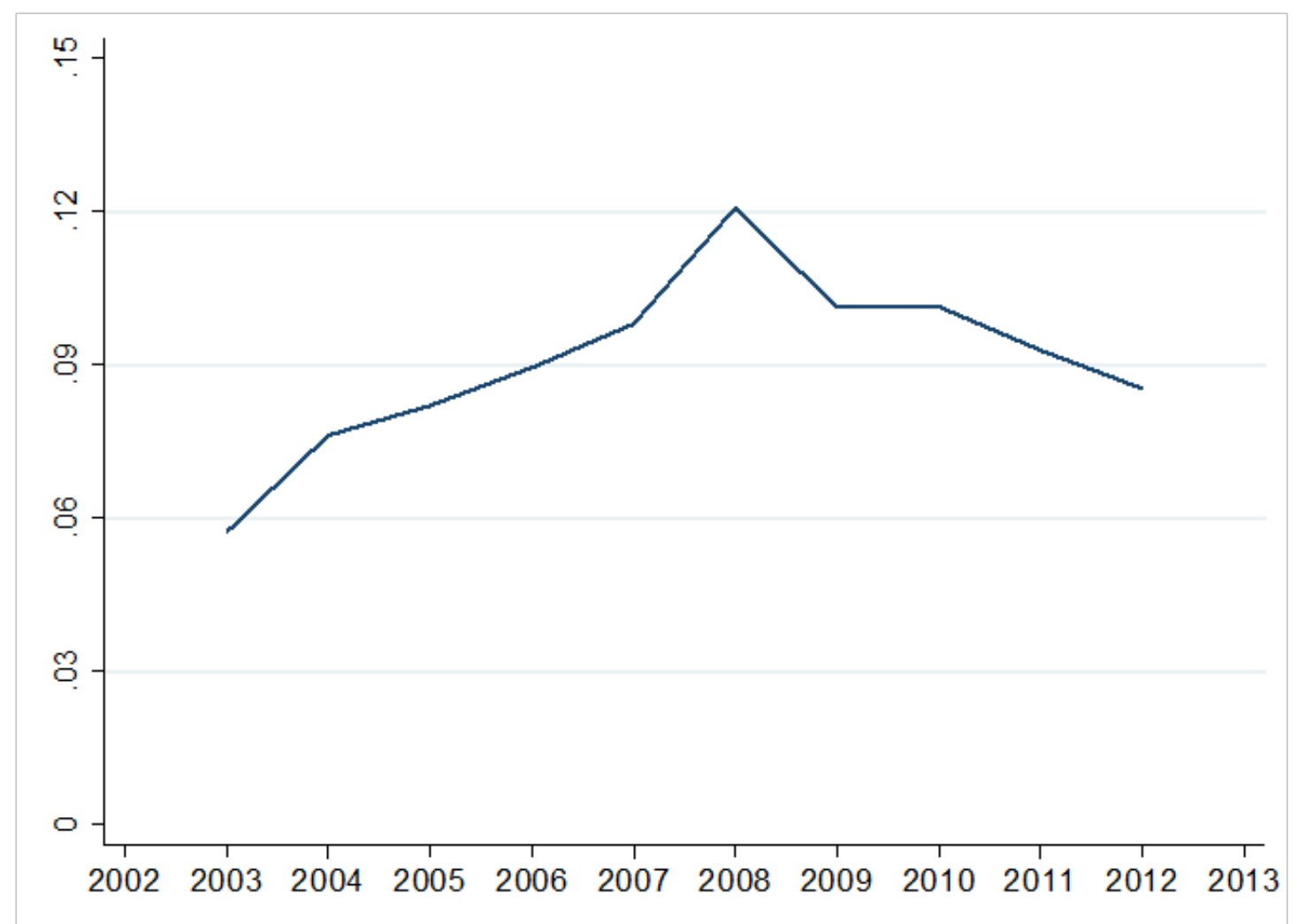


Figure 4. Efficiency transitions across the growth and economic slowdown periods

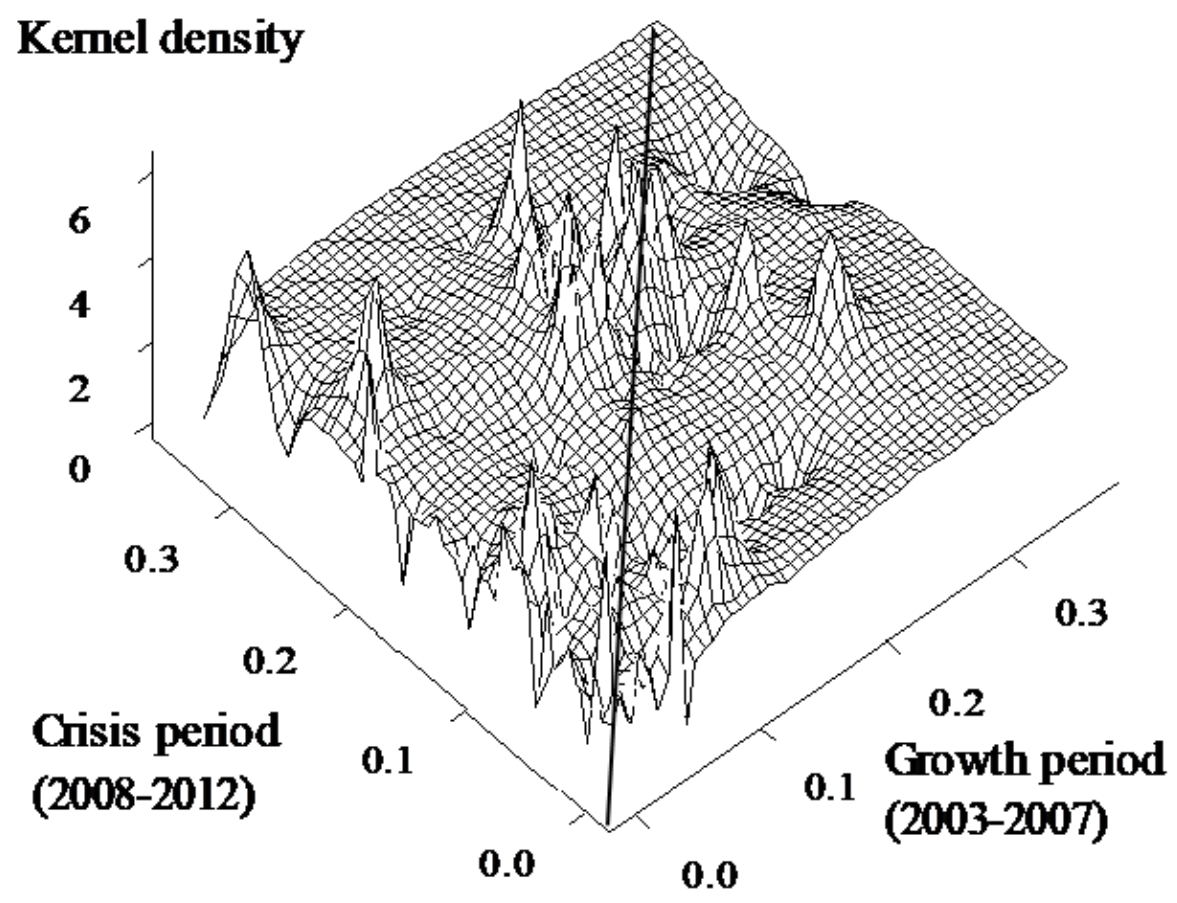




\section{List of Tables}

Table 1. Inputs and outputs: Average values for the period 2003-2012

\begin{tabular}{|l|l|l|r|r|r|r|}
\hline & $\begin{array}{l}\text { x1: } \\
\text { Workers } \\
\text { (thousand) }\end{array}$ & $\begin{array}{l}\text { x2: Number } \\
\text { of businesses } \\
\text { (thousand) }\end{array}$ & $\begin{array}{l}\text { x3: Safety } \\
\text { inspections } \\
\text { (thousand) }\end{array}$ & $\begin{array}{l}\text { x4: Safety } \\
\text { sanctions } \\
\text { (millions of } \\
\text { 2011 euro) }\end{array}$ & $\begin{array}{l}\text { y: GDP } \\
\text { (millions of } \\
\text { 2011 euro) }\end{array}$ & $\begin{array}{l}\text { b: Work } \\
\text { accidents } \\
\text { (thousand) }\end{array}$ \\
\hline 2003 & 399.24 & 56.12 & 9.24 & 1.79 & $12,537.57$ & 18.97 \\
\hline 2004 & 412.31 & 58.71 & 9.38 & 1.74 & $13,903.65$ & 19.06 \\
\hline 2005 & 426.20 & 61.13 & 9.75 & 2.01 & $15,589.03$ & 19.53 \\
\hline 2006 & 439.19 & 63.34 & 9.72 & 2.04 & $17,346.11$ & 20.26 \\
\hline 2007 & 451.94 & 66.58 & 8.56 & 2.28 & $19,319.79$ & 19.97 \\
\hline 2008 & 463.99 & 68.30 & 7.16 & 2.19 & $20,240.05$ & 17.32 \\
\hline 2009 & 463.24 & 66.97 & 7.19 & 1.50 & $19,631.39$ & 13.90 \\
\hline 2010 & 466.19 & 65.68 & 7.59 & 1.33 & $20,873.80$ & 12.89 \\
\hline 2011 & 467.36 & 64.87 & 7.33 & 1.20 & $21,420.32$ & 11.60 \\
\hline 2012 & 465.75 & 63.85 & 7.46 & 1.08 & $21,541.57$ & 9.40 \\
\hline Total & 445.54 & 63.55 & 8.34 & 1.72 & $18,240.33$ & 16.29 \\
\hline
\end{tabular}

Table 2. Efficiency scores: Summary statistics

\begin{tabular}{|r|r|c|c|c|c|}
\hline & \multicolumn{1}{|c|}{ Obs. } & Mean & Std. dev. & Q1 & Q3 \\
\hline 2003 & 50 & 0.0573 & 0.0781 & 0.0000 & 0.1021 \\
\hline 2004 & 50 & 0.0763 & 0.0945 & 0.0000 & 0.1556 \\
\hline 2005 & 50 & 0.0820 & 0.0931 & 0.0000 & 0.1710 \\
\hline 2006 & 50 & 0.0894 & 0.0938 & 0.0000 & 0.1656 \\
\hline 2007 & 50 & 0.0981 & 0.1115 & 0.0000 & 0.2223 \\
\hline 2008 & 50 & 0.1207 & 0.1112 & 0.0000 & 0.2214 \\
\hline 2009 & 50 & 0.1013 & 0.0926 & 0.0000 & 0.1921 \\
\hline 2010 & 50 & 0.1014 & 0.0886 & 0.0000 & 0.1870 \\
\hline 2011 & 50 & 0.0929 & 0.0863 & 0.0000 & 0.1667 \\
\hline 2012 & 50 & 0.0854 & 0.0777 & 0.0000 & 0.1513 \\
\hline Total & 500 & 0.0905 & 0.0939 & 0.0000 & 0.1711 \\
\hline
\end{tabular}

Note: Efficiency score are computed according to equation (1). 
Table 3. Efficiency scores by Autonomous Community

\begin{tabular}{|c|c|c|c|c|c|c|c|c|c|c|}
\hline \multirow[b]{2}{*}{ N } & \multirow[b]{2}{*}{ Province } & \multicolumn{3}{|c|}{ Efficiency scores (equation (2)) } & \multicolumn{3}{|c|}{ Safety inspections (thousand) } & \multicolumn{3}{|c|}{ Economic sanctions (millions of 2011 euro) } \\
\hline & & $\begin{array}{l}\text { Full } \\
\text { period }\end{array}$ & $\begin{array}{l}\text { Period } \\
2003-2007\end{array}$ & $\begin{array}{l}\text { Period } \\
2008-2012\end{array}$ & \begin{tabular}{|l|} 
Period \\
$2003-2007$
\end{tabular} & $\begin{array}{l}\text { Period } \\
2008-2012\end{array}$ & $\begin{array}{l}\text { Variation } \\
\text { rate }\end{array}$ & \begin{tabular}{|l|} 
Period \\
$2003-2007$
\end{tabular} & $\begin{array}{l}\text { Period } \\
2008-2012\end{array}$ & $\begin{array}{l}\text { Variation } \\
\text { rate }\end{array}$ \\
\hline 1 & Andalusia & 0.1655 & 0.1538 & 0.1773 & 11.14 & 10.17 & $-8.70 \%$ & 1.91 & 1.32 & $-30.95 \%$ \\
\hline 2 & Aragon & 0.0101 & 0.0104 & 0.0099 & 3.99 & 3.01 & $-24.59 \%$ & 0.96 & 1.02 & $5.77 \%$ \\
\hline 3 & Asturias & 0.0312 & 0.0316 & 0.0309 & 5.99 & 3.58 & $-40.19 \%$ & 1.24 & 0.78 & $-37.19 \%$ \\
\hline 4 & Balearic Islands & 0.1665 & 0.1380 & 0.1950 & 16.18 & 13.84 & $-14.48 \%$ & 2.49 & 2.40 & $-3.56 \%$ \\
\hline 5 & Canary Islands & 0.2115 & 0.2152 & 0.2079 & 11.25 & 8.25 & $-26.72 \%$ & 3.13 & 2.44 & $-22.21 \%$ \\
\hline 6 & Cantabria & 0.0967 & 0.0958 & 0.0977 & 5.19 & 3.74 & $-27.83 \%$ & 1.06 & 0.74 & $-30.05 \%$ \\
\hline 7 & Castile León & 0.0442 & 0.0415 & 0.0468 & 4.47 & 3.86 & $-13.67 \%$ & 0.45 & 0.44 & $-1.98 \%$ \\
\hline 8 & $\begin{array}{l}\text { Castile La } \\
\text { Mancha }\end{array}$ & 0.1415 & 0.1076 & 0.1754 & 3.10 & 3.91 & $26.44 \%$ & 0.84 & 0.67 & $-20.70 \%$ \\
\hline 9 & Catalonia & 0.0280 & 0.0207 & 0.0353 & 17.52 & 11.61 & $-33.72 \%$ & 4.37 & 3.21 & $-26.50 \%$ \\
\hline 10 & $\begin{array}{l}\text { Community of } \\
\text { Valencia }\end{array}$ & 0.0581 & 0.0696 & 0.0465 & 14.83 & 14.34 & $-3.30 \%$ & 3.08 & 2.47 & $-19.66 \%$ \\
\hline 11 & Extremadura & 0.1719 & 0.1453 & 0.1984 & 4.46 & 4.99 & $11.87 \%$ & 0.63 & 0.87 & $38.36 \%$ \\
\hline 12 & Galicia & 0.1150 & 0.0802 & 0.1499 & 5.99 & 5.82 & $-2.83 \%$ & 1.36 & 1.28 & $-5.93 \%$ \\
\hline 13 & Madrid & 0.0000 & 0.0000 & 0.0000 & 63.59 & 26.52 & $-58.29 \%$ & 13.11 & 7.89 & $-39.79 \%$ \\
\hline 14 & Murcia & 0.1710 & 0.1868 & 0.1553 & 16.99 & 10.06 & $-40.78 \%$ & 8.41 & 3.92 & $-53.36 \%$ \\
\hline 15 & Navarra & 0.0009 & 0.0010 & 0.0008 & 5.67 & 5.28 & $-6.76 \%$ & 1.17 & 0.94 & $-19.69 \%$ \\
\hline 16 & Basque Country & 0.0047 & 0.0021 & 0.0074 & 7.59 & 5.65 & $-25.56 \%$ & 1.40 & 0.95 & $-32.36 \%$ \\
\hline 17 & La Rioja & 0.0704 & 0.0647 & 0.0760 & 3.40 & 3.51 & $3.29 \%$ & 0.74 & 0.67 & $-9.34 \%$ \\
\hline & Total & 0.0905 & 0.0806 & 0.1003 & 9.33 & 7.35 & $-21.25 \%$ & 1.97 & 1.46 & $-25.81 \%$ \\
\hline
\end{tabular}

Note: Spanish provinces are grouped in the following Autonomous Communities: 1) Andalusia (Almeria, Cadiz, Córdoba, Granada, Huelva, Jaen, Malaga, Seville), 2)

Aragon (Huesca, Teruel, Zaragoza), 3) Asturias (Asturias), 4) Balearic Islands (Balearic Islands), 5) Canary Islands (Las Palmas, Sta. Cruz Tenerife), 6) Cantabria

(Cantabria), 7) Castile La Mancha (Albacete, Ciudad Real, Cuenca, Guadalajara, Toledo), 8) Castile Leon (Avila, Burgos, Leon, Palencia, Salamanca, Segovia, Soria,

Valladolid, Zamora), 9) Catalonia (Barcelona, Girona, Lleida, Tarragona), 10) Community of Valencia (Alicante, Castellon, Valencia), 11) Extremadura (Badajoz, Caceres),

12) Galicia (Coruña, Lugo, Ourense, Pontevedra), 13) Madrid (Madrid), 14) Murcia (Murcia), 15) Navarra (Navarra), 16) Basque Country (Alava, Guipúzcoa, Viscaya), La Rioja (La Rioja). 


\section{Appendix}

Appendix A. GAMS $\subseteq$ code used to compute the output-oriented directional distance function (DDF) that maximizes the desirable output and minimizes the bad output simultaneously

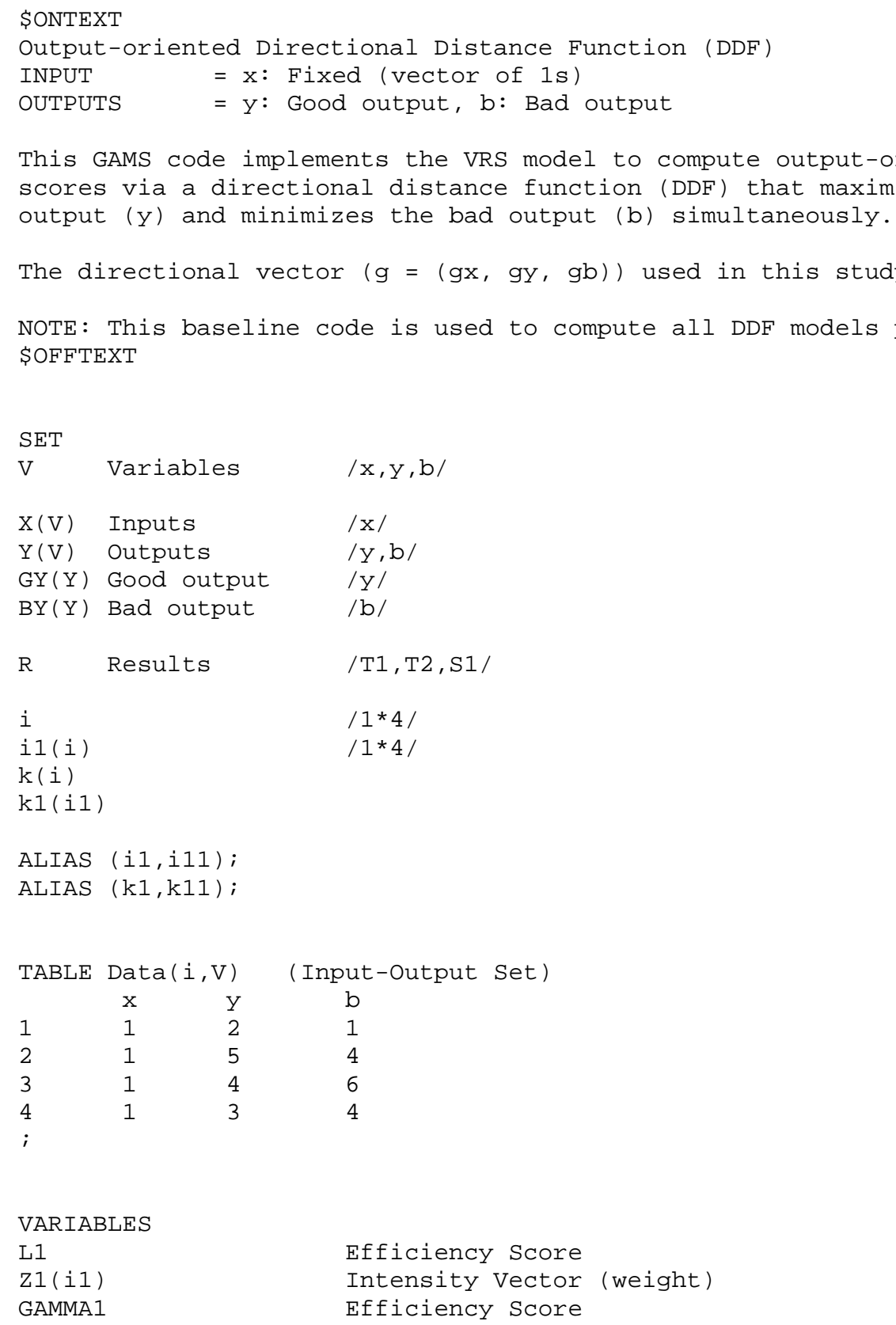

POSITIVE VARIABLE Z1;

PARAMETER

BETA1(i)

$\operatorname{IOTA1}(i, R)$

$R 11(i, R)$

$R 12(i, R)$

Efficiency Score

GAMMA1

SOLVESTAT Optimal VRS Model Solution

MODELSTAT Optimal VRS Model Syntax 
Appendix A. Continued.

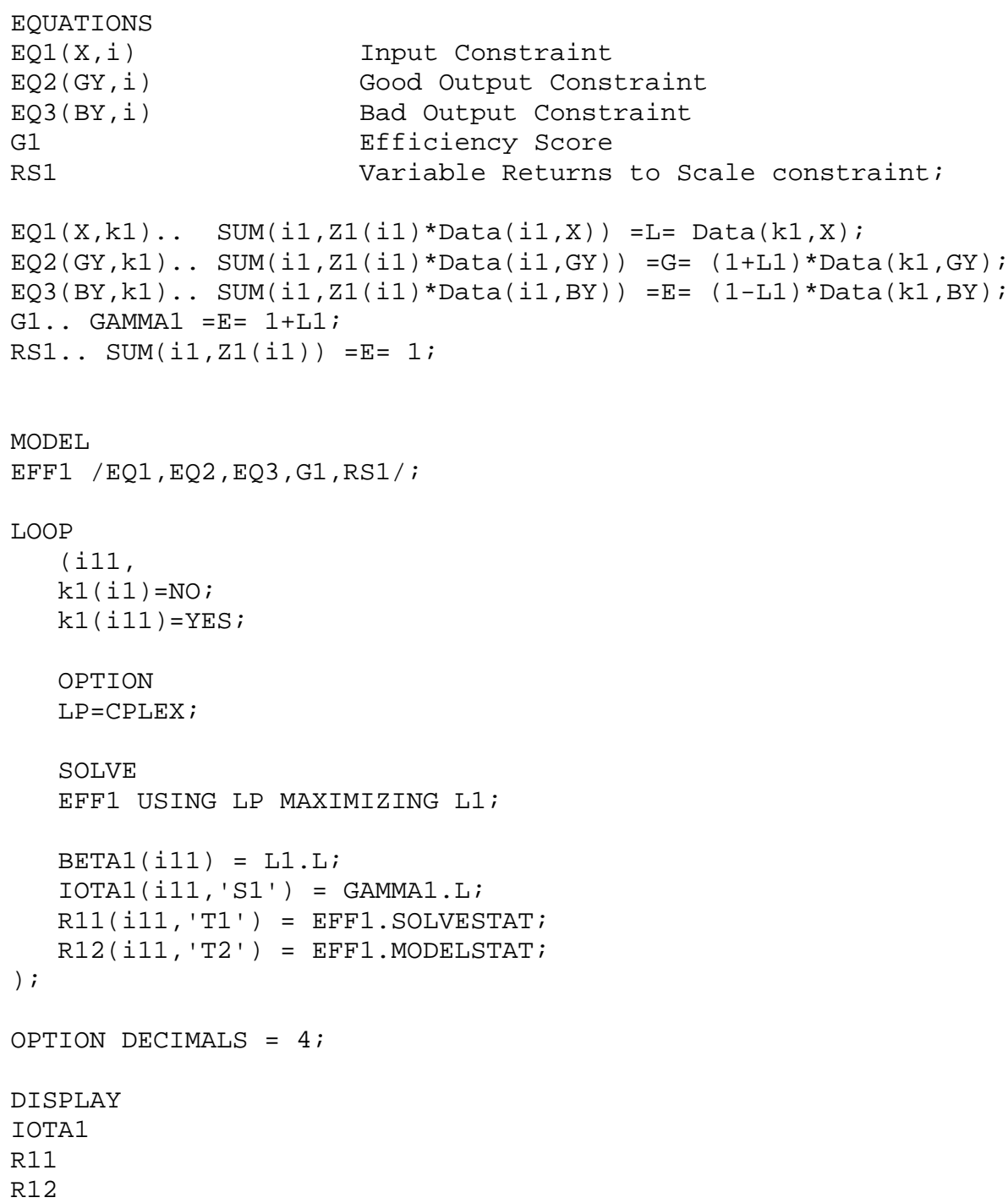

$\mathrm{R} 12$ 
Appendix B. Efficiency scores: Alternative specification

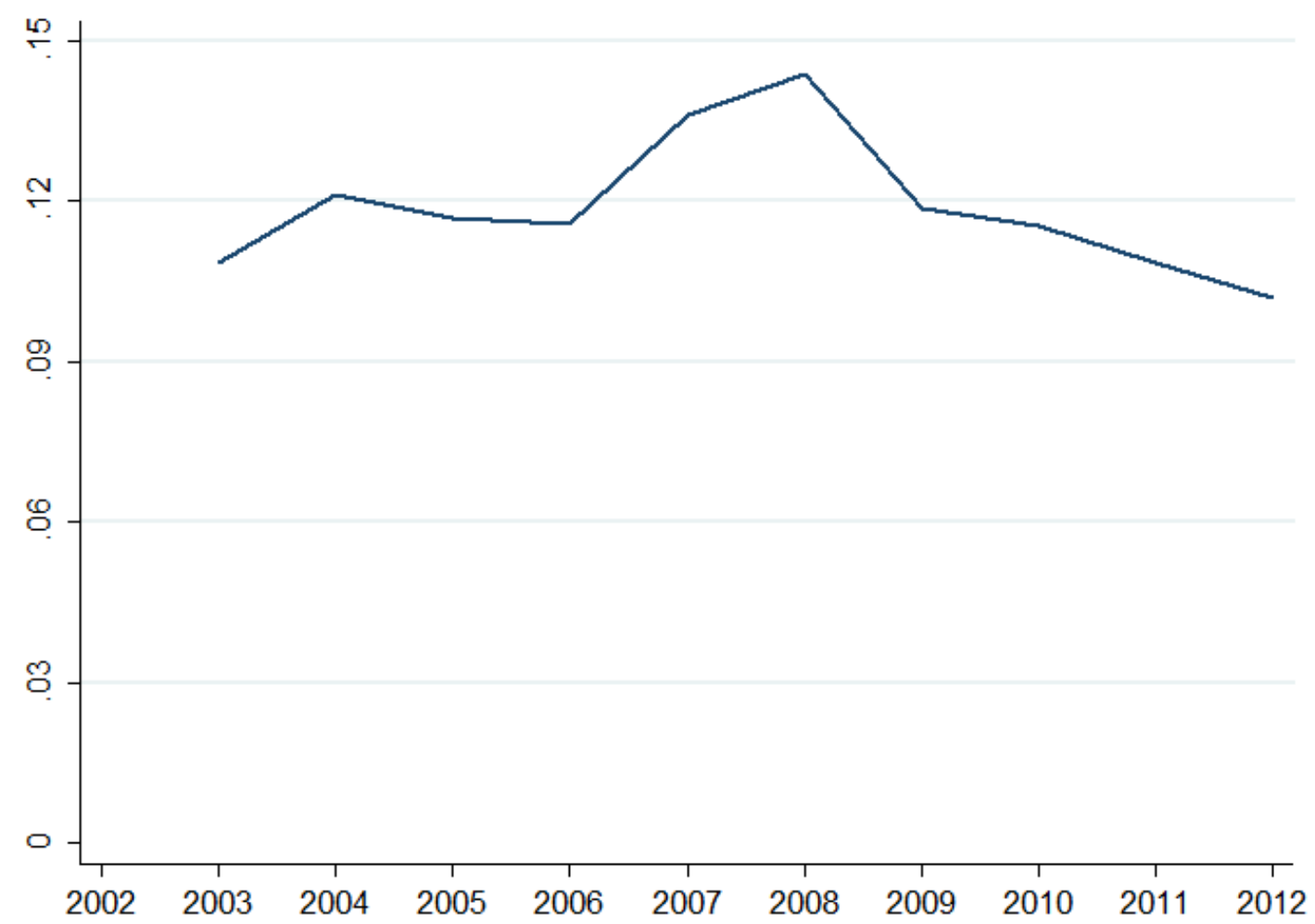


Appendix C. Efficiency scores of Spanish provinces

\begin{tabular}{|c|c|c|c|c|c|c|c|c|c|}
\hline $\mathrm{N}$ & Province & Full period & Period 2003-2007 & Period 2008-2012 & $\mathrm{N}$ & Province & Full period & Period 2003-2007 & Period 2008-2012 \\
\hline 1 & Álava & 0.0000 & 0.0000 & 0.0000 & 26 & Rioja, La & 0.0704 & 0.0647 & 0.0760 \\
\hline 2 & Albacete & 0.1692 & 0.1441 & 0.1943 & 27 & Lugo & 0.0672 & 0.0254 & 0.1089 \\
\hline 3 & Alicante & 0.0385 & 0.0444 & 0.0325 & 28 & Madrid & 0.0000 & 0.0000 & 0.0000 \\
\hline 4 & Almería & 0.1891 & 0.1640 & 0.2142 & 29 & Málaga & 0.2455 & 0.2855 & 0.2055 \\
\hline 5 & Ávila & 0.0051 & 0.0102 & 0.0000 & 30 & Murcia & 0.1710 & 0.1868 & 0.1553 \\
\hline 6 & Badajoz & 0.1998 & 0.1772 & 0.2225 & 31 & Navarra & 0.0009 & 0.0010 & 0.0008 \\
\hline 7 & Balearic Islands & 0.1665 & 0.1380 & 0.1950 & 32 & Ourense & 0.0435 & 0.0000 & 0.0871 \\
\hline 8 & Barcelona & 0.0455 & 0.0225 & 0.0685 & 33 & Asturias & 0.0312 & 0.0316 & 0.0309 \\
\hline 9 & Burgos & 0.0369 & 0.0000 & 0.0737 & 34 & Palencia & 0.0300 & 0.0488 & 0.0112 \\
\hline 10 & Cáceres & 0.1439 & 0.1135 & 0.1744 & 35 & Palmas, Las & 0.2361 & 0.2310 & 0.2412 \\
\hline 11 & Cádiz & 0.1659 & 0.1339 & 0.1978 & 36 & Pontevedra & 0.2154 & 0.1981 & 0.2326 \\
\hline 12 & Castellón & 0.0354 & 0.0371 & 0.0337 & 37 & Salamanca & 0.0187 & 0.0176 & 0.0198 \\
\hline 13 & Ciudad Real & 0.1355 & 0.0675 & 0.2036 & 38 & Sta. Cruz Tenerife & 0.1870 & 0.1994 & 0.1746 \\
\hline 14 & Córdoba & 0.0626 & 0.0492 & 0.0760 & 39 & Cantabria & 0.0967 & 0.0958 & 0.0977 \\
\hline 15 & Coruña, $\mathrm{A}$ & 0.1341 & 0.0973 & 0.1709 & 40 & Segovia & 0.0697 & 0.0691 & 0.0702 \\
\hline 16 & Cuenca & 0.0353 & 0.0285 & 0.0421 & 41 & Seville & 0.1440 & 0.0846 & 0.2034 \\
\hline 17 & Girona & 0.0472 & 0.0402 & 0.0541 & 42 & Soria & 0.0000 & 0.0000 & 0.0000 \\
\hline 18 & Granada & 0.1625 & 0.2013 & 0.1237 & 43 & Tarragona & 0.0006 & 0.0011 & 0.0000 \\
\hline 19 & Guadalajara & 0.1129 & 0.0519 & 0.1739 & 44 & Teruel & 0.0000 & 0.0000 & 0.0000 \\
\hline 20 & Guipúzcoa & 0.0000 & 0.0000 & 0.0000 & 45 & Toledo & 0.2545 & 0.2461 & 0.2630 \\
\hline 21 & Huelva & 0.2322 & 0.2179 & 0.2466 & 46 & Valencia & 0.1003 & 0.1274 & 0.0732 \\
\hline 22 & Huesca & 0.0034 & 0.0068 & 0.0000 & 47 & Valladolid & 0.0237 & 0.0113 & 0.0361 \\
\hline 23 & Jaén & 0.1225 & 0.0939 & 0.1512 & 48 & Vizcaya & 0.0141 & 0.0062 & 0.0221 \\
\hline 24 & León & 0.1799 & 0.1875 & 0.1722 & 49 & Zamora & 0.0336 & 0.0292 & 0.0381 \\
\hline \multirow[t]{2}{*}{25} & Lleida & 0.0189 & 0.0192 & 0.0186 & 50 & Zaragoza & 0.0270 & 0.0244 & 0.0297 \\
\hline & & & & & & Average & 0.0905 & 0.0806 & 0.1003 \\
\hline
\end{tabular}


Appendix D. Example: Empirical representation of the technology frontier for the year 2012

The objective of this supplementary analysis is to present, for a selected period (i.e., 2012), the empirically constructed technology frontier that expands good output (GDP) and reduces bad output (work accidents) simultaneously.

To facilitate the graphical representation of the results as well as the direct comparison between the theoretical frontier (Figures 1a and 1b) and the empirical technology presented in this analysis, we adopt an estimation approach in which the good and bad outputs are produced by a single constant input. This method—first proposed by Lovell and Pastor (1999) and further developed by, among others, Liu et al. (2011) and Karagiannis and Lovell (2016)—allows to accurately analyze problems in settings where input or output data are not available. Building on this literature, there are two main motivations to assess the efficiency of a set of units of analysis using DEA models without explicit inputs. First, several evaluation problems do not require input data and goals set by managers or policy makers become the objective of the analysis (e.g., Lo, 2010; Odeck, 2006). Second, in many cases outputs are aggregate variables (e.g., GDP per capita), and the data availability do not permit to distinguish the input levels necessary to produce the outputs (e.g., Cherchye et al., 2004; Despotis, 2005; Mizobuchi, 2014).

The supplementary analysis presented in this Appendix falls into the latter category. Under the assumption that input data are not available, the evaluation of how territories jointly maximize GDP and minimize work accidents is still a relevant economic problem that can be analyzed via a nonparametric model that uses a single constant input.

Therefore, we consider that the proposed DDF model that evaluates the joint production of GDP and work accidents constitutes an interesting extension of this literature. The following linear program—based on equation (1)—models the described technology $\left(\vec{D}_{O}(1, y, b)\right)$ :

$$
\begin{array}{lll}
\vec{D}_{O}\left(1_{i}, y_{i}, b_{i}\right)=\max \theta_{i} & \\
\text { subject to } & \sum_{i=1}^{N} \lambda_{i} y_{i, m} \geq(1+\theta)_{i} y_{i, m} & , m=1, \ldots, M \\
& \sum_{i=1}^{N} \lambda_{i} b_{i, k}=(1-\theta)_{i} b_{i, k} & , k=1, \ldots, K \\
& \sum_{i=1}^{N} \lambda_{i} x_{i, j} \leq 1 & , j=1 \forall i \\
& \sum_{i=1}^{N} \lambda_{i}=1 ; \lambda_{i} \geq 0 & , i=1, \ldots, N
\end{array}
$$

The solution value of $\theta$ is the efficiency score computed for the year 2012, and for efficient provinces $\theta=0$ while for inefficient provinces $\theta>0$ indicates the inefficiency level. The output vector includes the reported data for GDP (good output: $\mathbf{y}$ ) and work accidents (bad output: b) for 2012. The term $\lambda_{i}$ is the weight used to form the linear combinations of provinces $(N)$, and $\sum_{i=1}^{N} \lambda_{i}=1$ imposes variable returns to scale to the technology. The configuration of the input set is 
the only difference between the model used in this Appendix (equation (A1)) and the models estimated via equation (1): in this exercise we assume that the single constant input ( $\mathbf{x})$ is a $i \times 1$ vector of 1 s. Similar to equation (1), we choose the direction vector $\mathbf{g}=(0, y, b)$.

Note that in this Appendix we present the results for 2012 only. Summary statistics for the efficiency scores $(\theta)$ are presented in Table A1. To aid in the interpretation of the results, Figures A1a and A1b — which are the empirical representation of Figures 1a and 1b-display the empirically constructed technology frontier for the selected period along with scatterplots of the two outputs used in the model. Because of the large disparities in output values, there would be a poor visual resolution in the figures at low levels of GDP and work accidents. Thus, to ease the readability of the figures we only plotted the results for the efficient provinces on the frontier, and for two additional complementary cases (Barcelona and Seville).

Table A1. Supplementary analysis: Summary statistics for 2012

\begin{tabular}{|l|c|c|c|c|}
\hline & Mean & Std. dev. & Q1 & Q3 \\
\hline Efficiency score (equation (A1)) & 0.1135 & 0.0792 & 0.0494 & 0.1837 \\
\hline
\end{tabular}

Note: Sample size $=50$ observations (provinces).

The results of this exercise indicate that the average inefficiency level is $11.35 \%$ in 2012, and that four provinces are positioned on the efficiency frontier: Avila (Castille Leon), Madrid (Madrid), Soria (Castille Leon), and Tarragona (Catalonia) (these provinces are also efficient in the main model used in this study based on equation (1)).

Figures A1a and A1b demonstrate the intuition underlying our approach to computing the efficiency level of provinces in a model that accounts for the joint production of good and bad outputs. In the figures, we observe that efficiency is associated with a counter-clockwise production movement along the technology frontier. Therefore, for a given technology and input set, the reduction of bad outputs comes at the cost of a lower production of good outputs, relative to the case in which provinces can freely expand good and bad outputs.

For example, the estimated inefficiency level of Barcelona is 7.57\%. That is, instead of increasing the production of good and bad outputs to the hypothetical point 'Barcelona(h)', our model (equation (A1)) indicates that, to become efficient and reach the frontier in 2012 (point 'Barcelona*'), Barcelona should simultaneously expand its GDP and reduce its work accidents 7.57\%, while keeping its input level fixed (Figures A1a and A1b). A similar interpretation holds for Seville. To sum up, in a setting without safety controls economic agents would have incentives to freely dispose of their good and bad outputs, and efficiency analysis would place Seville in the hypothetical point 'Seville(h)' on the frontier. Yet, our model accurately assumes that the cost of reducing work accidents result from greater disciplinary controls that affect firms' activity, and indicates that with its current input level, 
Seville should jointly expand its GDP and reduce its work accidents $18.37 \%$ to operate efficiently (point 'Seville*').

Figure A1a. Production technology (1 input, 1 good output and 1 bad output) for 2012 (3D)

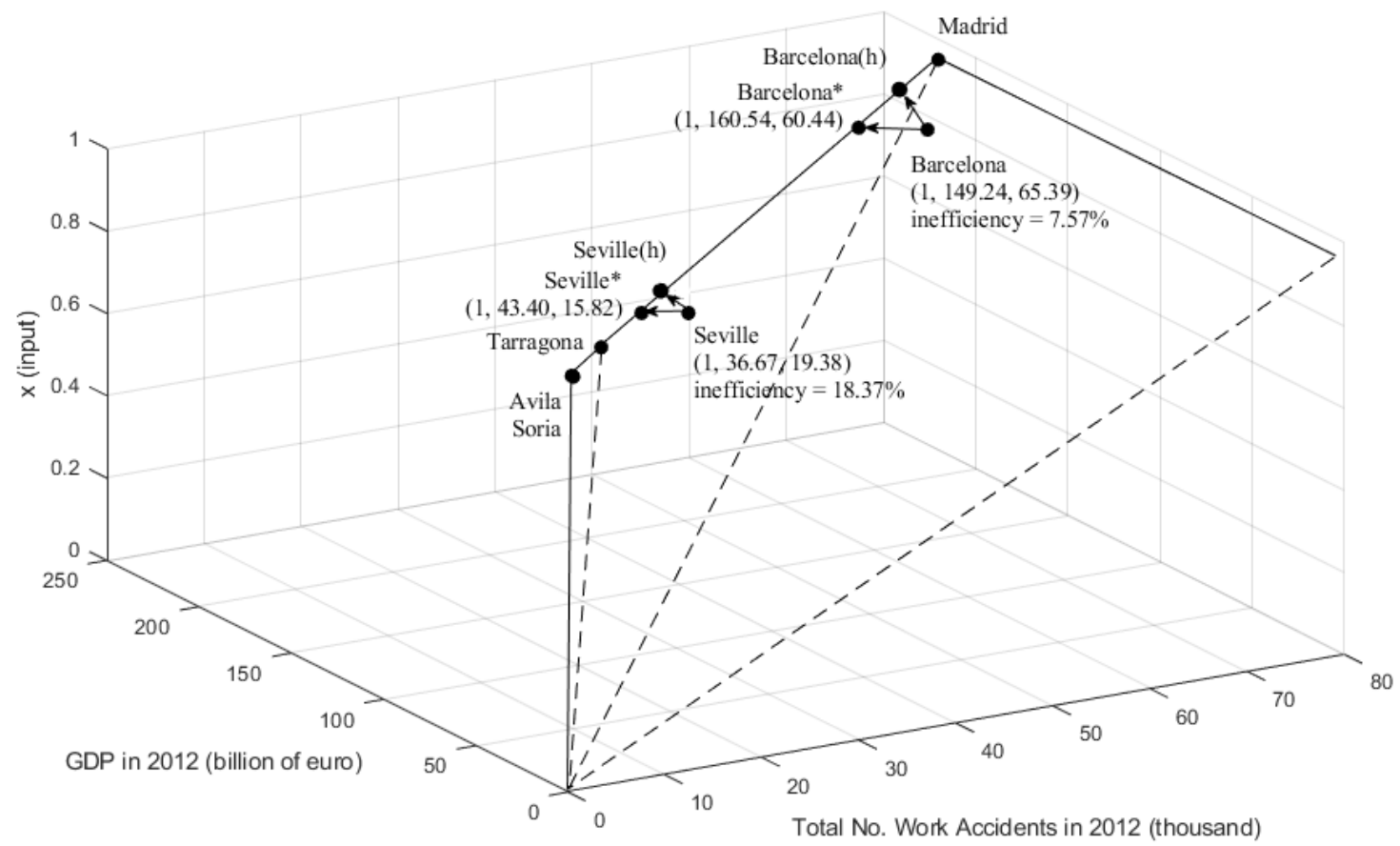

Source: Authors' elaboration (the efficiency scores were computed using GAMS $\odot$, while the figure was created using Matlab)

Figure A1b. Production technology (1 input, 1 good output and 1 bad output) for 2012 (2D)

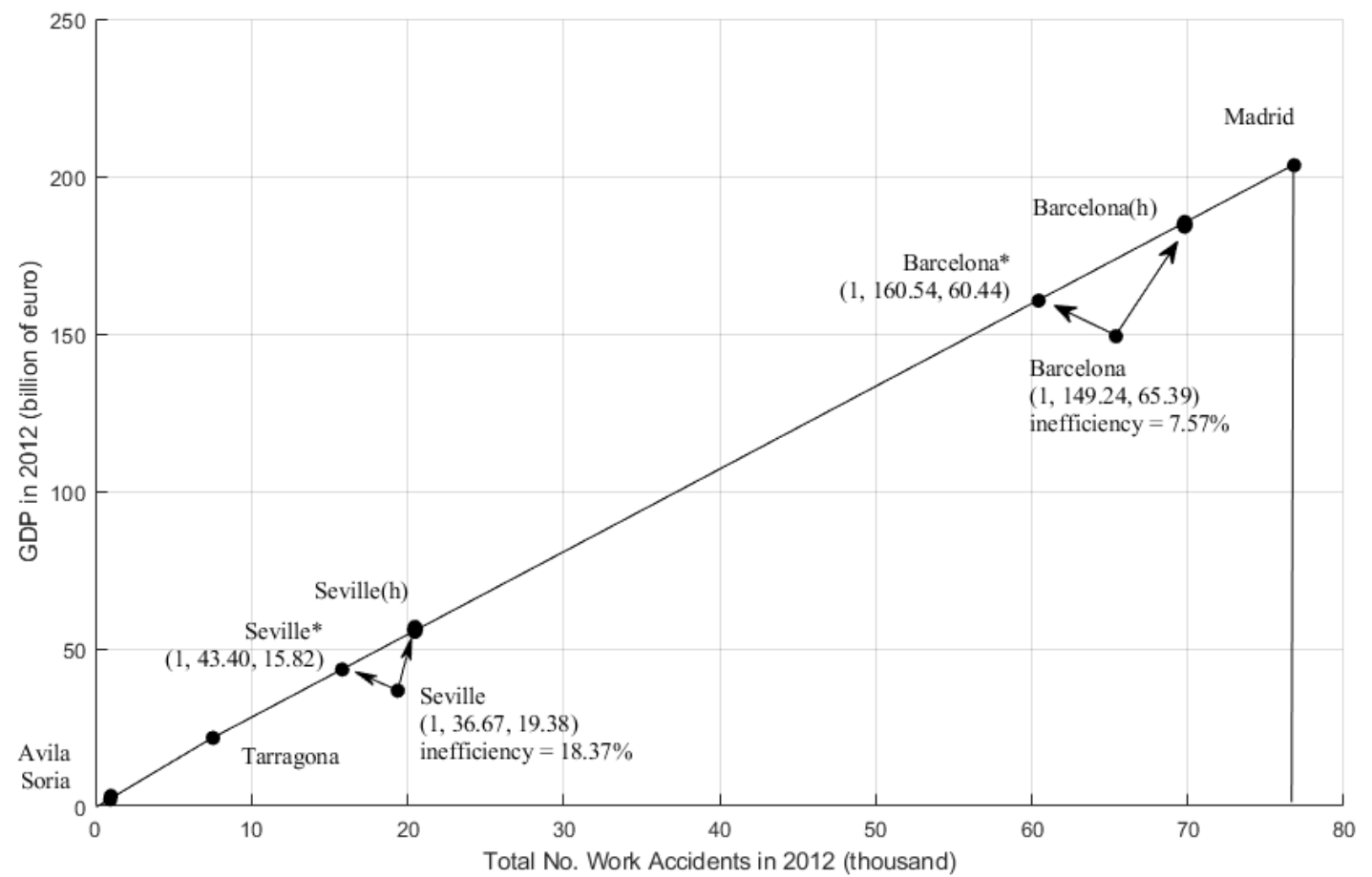

Source: Authors' elaboration (the efficiency scores were computed using GAMS $\odot$, while the figure was created using Matlab) 
Appendix E. Kernel density estimates: Efficiency scores in growth and slowdown periods

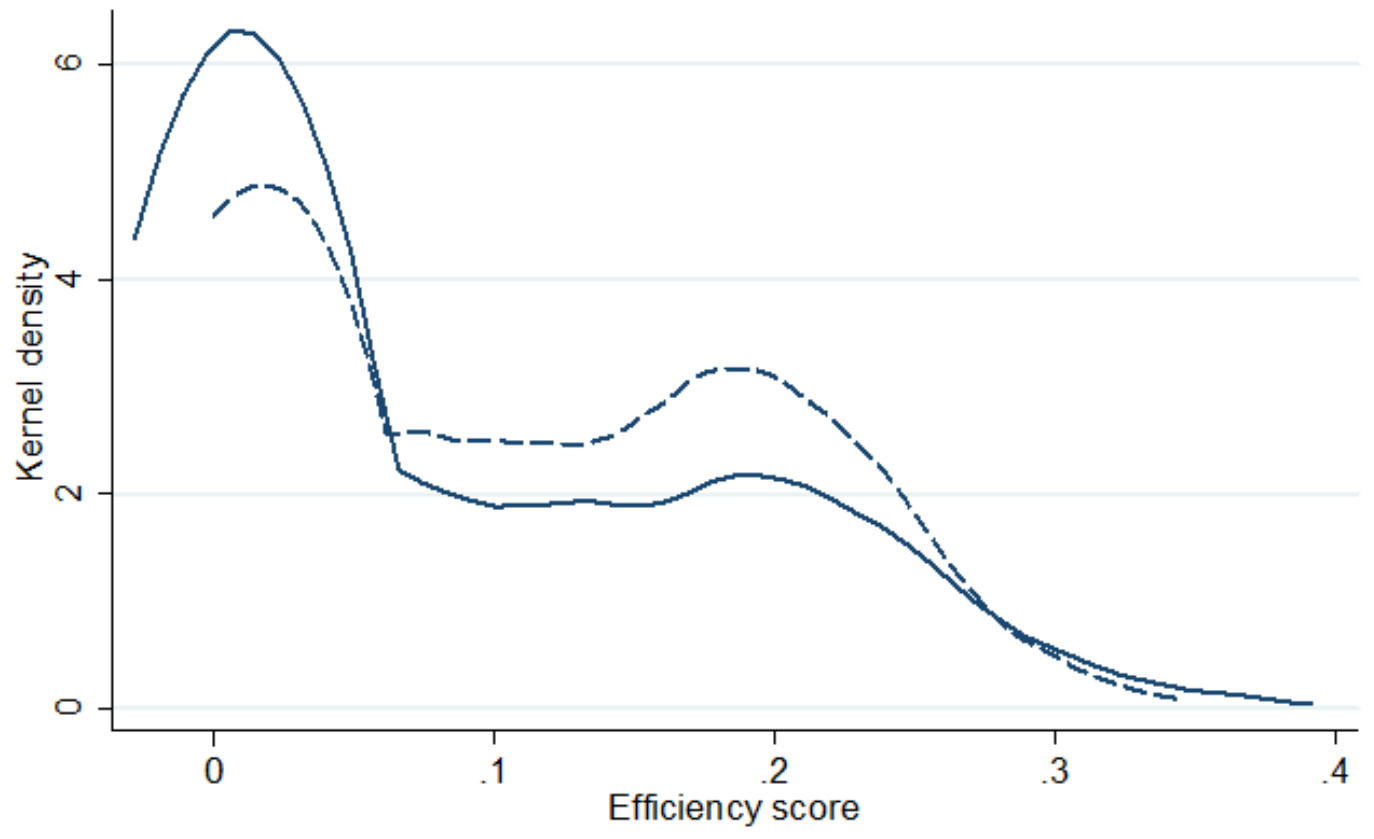

Period 2003-2007

Period 2008-2012

kernel $=$ epanechnikov , bandwidth $=0.0284$ 
Appendix F. Robustness check: Industry mix and work accident rates

We conducted a second supplementary analysis to evaluate the relationship between the configuration of the local industry mix and the rate of work accidents. For each province, the rate of work accidents is defined as the total number of work accidents divided by the total number of workers, while the industry mix is measured by the proportion of establishments in extractive, manufacturing, construction, and service sectors. We use the number of establishments to calculate the relative weight of each industry because data on the industry distribution of businesses is not available from the INE databases for the period 2003-2007

(http://ine.es/dyngs/INEbase/en/operacion.htm?c=Estadistica_C\&cid=1254736161927\&menu=resulta dos\&idp=1254735576550), while comparable data at the establishment level are available from the INE’s Central Business Register for the study period (2003-2012) (the data was obtained from: http://ine.es/dynt3/inebase/en/index.htm?padre=53\&capsel=3925). Descriptive statistics are presented in Table A2. The estimated regression model has the following form:

Rate of work accidents ${ }_{i t}=\beta_{0}+\beta_{1}$ Industry mix $_{i t}+\beta_{1}$ Controls $_{i t}+\varepsilon_{i t}$

Equation (A2) is computed via fixed-effects estimator. We control for economic performance (GDP per capita), industry size (total number of establishments), changes in the economic cycle measured by a dummy variable ('Crisis') taking the value of one for the period 2008-2012, and a set of time dummies that rule out potential unobserved factors that have a homogeneous impact on the rate of work accidents. Note that the variables GDP per capita and industry size are logged to reduce skewness. The error term $\left(\varepsilon_{i t}=\eta_{i}+\nu_{i t}\right)$ includes an unobserved province-specific time-invariant effect $\left(\eta_{i}\right)$ that account for unobservable heterogeneity and a stochastic disturbance $\left(\nu_{i t}\right)$ that varies cross-provinces and cross-time.

In line with the descriptive results presented in Section 4 (Figure 2), regression results in Table A3 reveal that the rate of work accidents falls down in periods of economic slowdown. Additionally we observe that, relative to establishments in service sectors, provinces with a greater proportion of establishments in the construction sector report a significantly higher rate of work accidents. Consistent with the findings reported in prior research (e.g., Lafuente and Abad, 2018; Wiengarten et al., 2017), this result suggests that establishments in the construction industry are more accident prone than establishments in service sectors. 
Table A2. Supplementary analysis: Summary statistics (period 2003-2012)

\begin{tabular}{|l|c|c|}
\hline & Mean & Std. dev. \\
\hline $\begin{array}{l}\text { Rate of work accidents } \\
\text { (total accidents / total number of workers) }\end{array}$ & 3.5874 & 1.1394 \\
\hline Total number of establishments & $70,915.14$ & $97,168.25$ \\
\hline Proportion of establishments: Manufacturing & 0.0802 & 0.0197 \\
\hline Proportion of establishments: Construction industry & 0.1449 & 0.0259 \\
\hline Proportion of establishments: Service sectors & 0.7731 & 0.0367 \\
\hline Proportion of establishments: Extractive sectors & 0.0018 & 0.0014 \\
\hline GDP per capita & $18,949.17$ & $4,679.16$ \\
\hline
\end{tabular}

Note: Sample size $=500$ observations (provinces).

Table A3. Fixed-effects regression results: Industry mix and work accident rates

\begin{tabular}{|l|c|}
\hline & $\begin{array}{l}\text { Dependent variable } \\
\text { Work accident rate }\end{array}$ \\
\hline Proportion of establishments: Manufacturing & $1.3346(1.8781)$ \\
\hline Proportion of establishments: Construction industry & $2.1870(0.9369)^{* *}$ \\
\hline Proportion of establishments: Extractive sectors & $7.4287(9.1468)$ \\
\hline GDP per capita (log value) & $0.4536(0.1684)^{* * *}$ \\
\hline Total number of establishments (log value) & $-0.1877(0.2165)$ \\
\hline Crisis (dummy) & $-0.8594(0.0832)^{* * *}$ \\
\hline Time dummies & Yes \\
\hline Intercept & $5.8970(2.9342)^{* *}$ \\
\hline F test & $341.52^{* * *}$ \\
\hline R2 (within) & 0.8233 \\
\hline Average VIF (minimum-maximum) & $2.01(1.20-5.22)$ \\
\hline Number of observations & 500 \\
\hline
\end{tabular}

Robust standard errors are presented in brackets. *, **, *** indicate significance at the $10 \%, 5 \%$ and $1 \%$, respectively. 